\title{
Annotated Bibliography of Literature Addressing Low-Income Energy Affordability in the United States
}

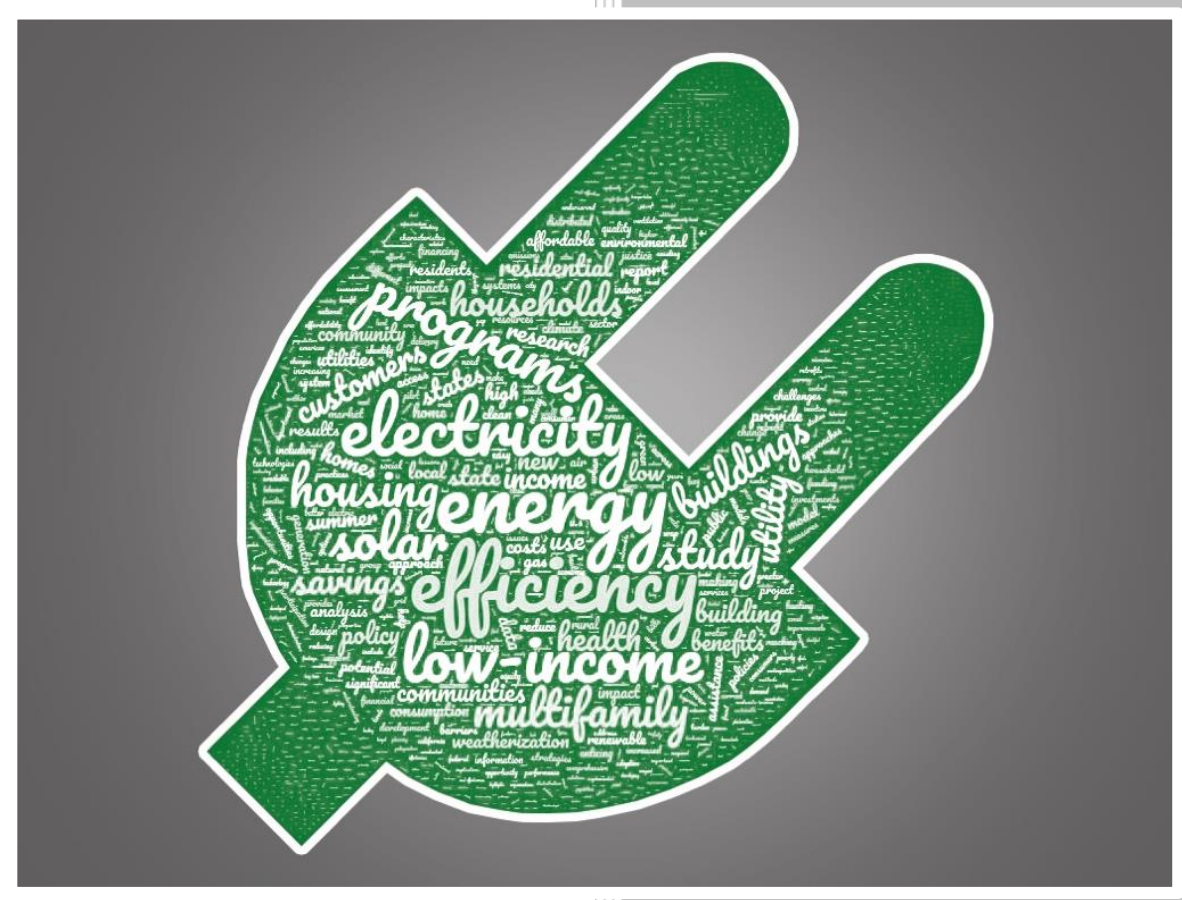

Melissa V. Lapsa Marilyn A. Brown Anmol Soni

March 2020 


\title{
DOCUMENT AVAILABILITY
}

Reports produced after January 1, 1996, are generally available free via US Department of Energy (DOE) SciTech Connect.

Website www.osti.gov

Reports produced before January 1, 1996, may be purchased by members of the public from the following source:

\author{
National Technical Information Service \\ 5285 Port Royal Road \\ Springfield, VA 22161 \\ Telephone 703-605-6000 (1-800-553-6847) \\ TDD 703-487-4639 \\ Fax 703-605-6900 \\ E-mail info@ntis.gov \\ Website http://classic.ntis.gov/
}

Reports are available to DOE employees, DOE contractors, Energy Technology Data Exchange representatives, and International Nuclear Information System representatives from the following source:

Office of Scientific and Technical Information

PO Box 62

Oak Ridge, TN 37831

Telephone 865-576-8401

Fax 865-576-5728

E-mail reports@osti.gov

Website http://www.osti.gov/contact.html

This report was prepared as an account of work sponsored by an agency of the United States Government. Neither the United States Government nor any agency thereof, nor any of their employees, makes any warranty, express or implied, or assumes any legal liability or responsibility for the accuracy, completeness, or usefulness of any information, apparatus, product, or process disclosed, or represents that its use would not infringe privately owned rights. Reference herein to any specific commercial product, process, or service by trade name, trademark, manufacturer, or otherwise, does not necessarily constitute or imply its endorsement, recommendation, or favoring by the United States Government or any agency thereof. The views and opinions of authors expressed herein do not necessarily state or reflect those of the United States Government or any agency thereof. 
Energy and Transportation Science Division

\section{ANNOTATED BIBLIOGRAPHY OF LITERATURE ADDRESSING LOW-INCOME ENERGY AFFORDABILITY IN THE UNITED STATES}

Melissa V. Lapsa, Oak Ridge National Laboratory

Marilyn A. Brown, Georgia Institute of Technology

Anmol Soni, Georgia Institute of Technology

March 2020

Prepared by

OAK RIDGE NATIONAL LABORATORY

Oak Ridge, TN 37831-6283

managed by

UT-BATTELLE, LLC

for the

US DEPARTMENT OF ENERGY

under contract DE-AC05-00OR22725 



\section{CONTENTS}

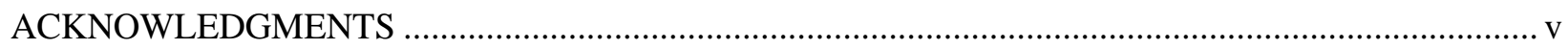

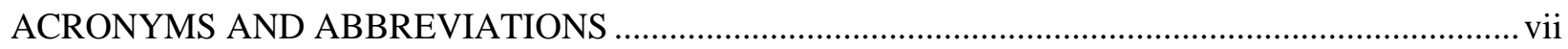

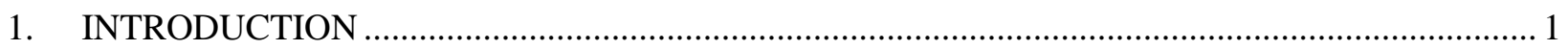

2. ABSTRACTS AND CITATIONS FOR THE IDENTIFIED REFERENCES ………....................... 5 



\section{ACKNOWLEDGMENTS}

This annotated bibliography was produced for the Strategic \& Interagency Initiatives group within the US Department of Energy's Weatherization and Intergovernmental Program Office, under the management of Pam Mendelson and Michael DiRamio. Funding for this research was gratefully provided by the US Department of Energy and the Brook Byers Institute for Sustainable Systems at the Georgia Institute of Technology.

We are appreciative of several organizations for facilitating our access to their publications. This includes the Distributed Energy Financial Group's Low-Income Energy Issues Forum and the American Council for an Energy Efficient Economy.

Helpful assistance with this bibliography was provided by Charlotte Franchuk (Data Support Services) and Ranal Tudawe and Ameet Doshi (Georgia Institute of Technology). Any remaining errors are the sole responsibility of the authors. 



\section{ACRONYMS AND ABBREVIATIONS}

ACEEE

DOE

HVAC

LMI

ORNL

PM

PV

WAP
American Council for an Energy Efficient Economy

US Department of Energy

heating, ventilation, and air conditioning

low and moderate income (or low to moderate income)

Oak Ridge National Laboratory

particulate matter

photovoltaic

Weatherization Assistance Program 



\section{INTRODUCTION}

Oak Ridge National Laboratory (ORNL), with support from the Georgia Institute of Technology, conducted a "meta review" of low-income energy affordability in the United States (Brown, et al., 2020). The first step of that review involved the creation of an annotated bibliography of literature focused on low-income household energy affordability, needs, and gaps. This bibliography includes abstracts of the published literature discussed in the meta review.

This annotated bibliography describes the relatively current literature (published from 2010 to 2019) that examines low-income energy affordability in the United States. As an initial search criterion, literature was compiled from journal publications archived in Web of Science and Scopus databases. The following syntax, which combines three dimensions, was used to identify the journal articles:

1. A focus on low-income households (low-income OR low income OR subsidized housing OR equity OR poverty OR fuel poverty OR energy justice OR socioeconomic OR environmental justice OR consumer access OR affordable OR energy burden)

2. Coverage of energy efficiency or behind-the-meter low-carbon energy supply (energy efficiency OR energy efficient OR household space cooling OR household air conditioning OR household space heating OR energy conservation OR energy retrofit OR energy improvements OR weatherization OR weatherisation OR low carbon OR solar OR solar panel OR solar panels OR photovoltaic)

3. Analysis of the costs and benefits of alternative solutions (program evaluation OR efficacy OR effect OR cost-benefit OR cost benefit OR benefit cost OR benefit-cost OR analysis OR policy analysis OR programme evaluation OR impact OR incentive)

When conducted in July 2019, the search identified 270 references. The abstracts of each of these references were evaluated and "tagged" by two experts, resulting in a "curated" database of 80 references. Many of the 270 journal articles were eliminated because they focused on countries other than the United States or they principally covered non-low-income energy affordability issues.

A second set of references was derived from three amplification processes that identified key publications not archived in the Web of Science and Scopus databases.

1. Additional peer-reviewed literature was identified that is not archived in the Web of Science or Scopus databased. For example, numerous formally peer reviewed U.S. Department of Energy (DOE) reports were added to the bibliography, along with reports by DOE national laboratories and by state and local government agencies. These additions brought the total number of documents to 96 .

2. Additional literature was identified that derived from publications of key stakeholder groups in the affordable energy arena. These organizations follow a range of document 
review procedures. They include, for instance, publications of the Distributed Energy Financial Group's Low-Income Energy Issues Forum as well as conference proceedings and other publications of the American Council for an Energy Efficient Economy (ACEEE). An additional 75 documents were included as a result of this amplification process, bringing the total number of annotated publications to 171 .

3. Finally, an extensive evaluation of the associated meta review identified 12 additional references that needed to be added to the annotated bibliography. This increased the number of publications included in the final annotated bibliography to 183 .

The abstracts published in this annotated bibliography are not copyright protected. To achieve this open source status, each of the abstracts was rewritten for inclusion in this annotated bibliography. Approximately $10 \%$ of the documents did not have abstracts; therefore, abstracts were written based on a review of the document. In some cases, abstracts were quite short and were lengthened, and in other cases they were quite long and were shortened. Finally, all of the documents were tagged using topical abbreviations that allow users to navigate the annotated bibliography in a systematic way (Table 1).

Table 1. Topics covered by the annotated bibliography

\begin{tabular}{|l|c|l|c|}
\hline \multicolumn{1}{|c|}{ Tag Name } & Frequency & \multicolumn{1}{|c|}{ Description } & $\begin{array}{c}\text { Search } \\
\text { Text }\end{array}$ \\
\hline $\begin{array}{l}\text { Programs \& } \\
\text { Services }\end{array}$ & 118 & $\begin{array}{l}\text { Studies that describe low-income energy programs, services, } \\
\text { and technologies, including what markets are served and } \\
\text { how they are served. }\end{array}$ & XPRO \\
\hline $\begin{array}{l}\text { Behavioral } \\
\text { Economics \& } \\
\text { Social Sciences }\end{array}$ & 64 & $\begin{array}{l}\text { Studies analyzing the purchase behavior and energy use } \\
\text { patterns of households and their responsiveness to program } \\
\text { messaging, education, information feedback, and social } \\
\text { media. }\end{array}$ & XBES \\
\hline $\begin{array}{l}\text { Characterization } \\
\text { Mosts \& Benefits }\end{array}$ & 51 & $\begin{array}{l}\text { Studies that describe the characteristics of the low-income } \\
\text { population, such as its size, ethnicity, education, and } \\
\text { geography. }\end{array}$ & XCHA \\
\hline $\begin{array}{l}\text { Lolar Energy for } \\
\text { Households }\end{array}$ & 40 & $\begin{array}{l}\text { Studies that document the cost effectiveness of low-income } \\
\text { energy programs, including studies of nonenergy benefits. }\end{array}$ & XCBA \\
\hline $\begin{array}{l}\text { Sauses, } \\
\text { Correlates, \& } \\
\text { Effects }\end{array}$ & 33 & $\begin{array}{l}\text { Solar energy in low-income housing. Utility-scale, rooftop, } \\
\text { and community solar are all included here. }\end{array}$ & XSOL \\
\hline Sigh energy burden. & $\begin{array}{l}\text { Studies analyzing energy programs in low-income } \\
\text { multifamily and rental housing, including studies of split } \\
\text { incentives. }\end{array}$ & XMUL \\
\hline
\end{tabular}




\begin{tabular}{|c|c|c|c|}
\hline Tag Name & Frequency & Description & $\begin{array}{c}\text { Search } \\
\text { Text }\end{array}$ \\
\hline Data Analytics & 22 & $\begin{array}{l}\text { Studies that examine the role of data in program design, } \\
\text { implementation, and evaluation. In particular, those focusing } \\
\text { on novel ways of collecting, interpreting, and presenting } \\
\text { data. }\end{array}$ & XDAT \\
\hline $\begin{array}{l}\text { Building, } \\
\text { Envelope, HVAC } \\
\text { \& Appliance } \\
\text { Technologies }\end{array}$ & 22 & $\begin{array}{l}\text { Studies focusing on the implementation of new hardware } \\
\text { and technologies that help reduce energy consumption } \\
\text { through improved building envelopes, HVAC, and } \\
\text { appliances. }\end{array}$ & XTEC \\
\hline Health Effects & 21 & $\begin{array}{l}\text { Studies that explicitly document the health benefits of } \\
\text { energy programs for low- to moderate-income households. } \\
\text { The benefits could be monetary as well as nonmonetary. }\end{array}$ & XHEA \\
\hline $\begin{array}{l}\text { Information \& } \\
\text { Communication } \\
\text { Technologies }\end{array}$ & 13 & $\begin{array}{l}\text { Studies relating to the implementation of new information } \\
\text { and data collection tools that help monitor, control, and } \\
\text { reduce energy consumption for low- and moderate-income } \\
\text { households. }\end{array}$ & XICT \\
\hline $\begin{array}{l}\text { Rural } \\
\text { Communities }\end{array}$ & 11 & $\begin{array}{l}\text { Studies that investigate energy affordability and energy } \\
\text { access programs in rural areas, island territories, and Indian } \\
\text { reservations. }\end{array}$ & XRUR \\
\hline Grid Resilience & 8 & $\begin{array}{l}\text { Studies focusing on the effect of energy programs on grid } \\
\text { resilience, stability, and reliability, including smart grids and } \\
\text { supporting policies. }\end{array}$ & XGRI \\
\hline $\begin{array}{l}\text { Manufactured \& } \\
\text { Mobile Homes }\end{array}$ & 5 & $\begin{array}{l}\text { Studies focusing on the energy consumption patterns and } \\
\text { effectiveness of programs for households living in } \\
\text { manufactured and mobile homes. }\end{array}$ & XMAN \\
\hline
\end{tabular}

The Programs and Services tag (i.e., "Studies that describe energy programs, services, and technologies, including what markets are served and how they are served") is the most common tag. At the other extreme, the Manufactured and Mobile Homes tag (i.e., "Studies focusing on the energy consumption patterns and effectiveness of programs for households living in manufactured and mobile homes") is the least frequent.

For an in-depth assessment of the contents of these documents, please refer to the following report: Brown, Marilyn A., Anmol Soni, Melissa V. Lapsa, and Katie Southworth. 2020. LowIncome Energy Affordability: Conclusions from a Literature Review, (Oak Ridge, TN: Oak Ridge National Laboratory), ORNL/TM-2019/1150. 


\section{ABSTRACTS AND CITATIONS FOR THE IDENTIFIED REFERENCES}

Allcott, Hunt, and Dmitry Taubinsky. 2015. "Evaluating Behaviorally Motivated Policy: Experimental Evidence from the Lightbulb Market." American Economic Review, 105(8): 250138. https://pubs.aeaweb.org/doi/pdfplus/10.1257/aer.20131564.

This paper evaluates motivations in the light bulb market using a theoretical model and two randomized experiments. Welfare effects are derived as functions of reduced-form sufficient statistics capturing economic and psychological parameters. These are estimated using a novel within-subject information disclosure experiment. Results suggest that moderate subsidies for energy-efficient light bulbs might increase welfare, although informational and attentional biases alone do not justify an incandescent light bulb ban. The paper provides broader methodological insights into welfare analysis with mis-optimizing consumers.

Tags: XPRO, XTEC, XBES

Allcott, H., and T. Rogers. 2014. "The short-run and long-run effects of behavioral interventions: Experimental evidence from energy conservation." American Economic Review, 104(10), 300337. https://www.aeaweb.org/articles?id=10.1257/aer.104.10.3003.

The paper documents three features of the Opower program, in which social comparisonbased home energy reports are mailed repeatedly to over six million American households. Initial reports cause high-frequency "action and backsliding," although these cycles attenuate in time. If reports discontinue after two years, effects decay at 10-20\% each year, remaining relatively persistent. Consumers appear slow to habituate, continuing to respond to repeated treatment even after two years. The results show how empirical estimates can be used to optimize program design.

Tags: XPRO, XDAT

Andrews, Adrian, and Sarah Poe. 2018. "Reaching the Underserved: A Collaborative Approach to Serving Income Qualified Customers." 2018 ACEEE Summer Study on Energy Efficiency in Buildings: Making Efficiency Easy and Enticing. https://aceee.org/files/proceedings/2018/index.html\#/paper/event-data/p388.

This paper investigates a no-cost weatherization program serving income-qualified customers. The basis for this approach is partnership with nonprofit organizations that combine weatherization and housing funding sources, including the Home Weatherization Assistance Program and weatherization programs run by electric utilities, to have the biggest impact on customers. Targeting high-usage, high-arrearage customers from rural, suburban, and urban areas, a community-based approach was piloted in the southeastern Ohio cities of Nelsonville and Murray City, where energy efficiency programs had been offered to all residents. Conversations between neighbors, door-todoor canvassing, and engagement with landlords, businesses, and local officials boosted 
participation and heightened awareness of the benefits of energy efficiency. An underserved rental market realized energy efficiency and improvements in health and safety benefiting both tenants and landlords. Local community action agencies provided heating and weatherization services, adding crews to meet customer demand. It is expected that this approach is replicated in other communities. The lessons learned resulted in program policy changes benefitting even more income-eligible, yet underserved consumers.

Tags: XMUL, XPRO

Aznar, A. Y., and D. A. Gagne. 2018. Low-Income Community Solar: Utility Return Considerations for Electric Cooperatives. No. NREL/TP-7A40-70536. National Renewable Energy Laboratory, Golden, CO. https://www.nrel.gov/docs/fy18osti/70536.pdf.

This paper briefly identifies project structures making low-income community solar projects more scalable, replicable, and cost-effective for electric cooperative and municipal utilities. The report explores the tradeoffs between utility project returns and providing energy bill savings for low-income subscribers, as well as some of the key lessons learned from previously successful solar pilot projects in low-income communities.

\section{Tags: XPRO, XSOL, XCBA}

Barbier, E. B. 2014. "Climate change mitigation policies and poverty." Wiley Interdisciplinary Reviews-Climate Change, 5(4): 483-491. http://wires.wiley.com/WileyCDA/WiresArticle/wisId-WCC281.html.

Climate change mitigation policies can directly or indirectly affect poverty in developing countries. Direct impacts include payments for avoided deforestation that affect the livelihoods of the poor, benefits of improved air quality and health as a result of reduced greenhouse gas emissions, and the effects of clean energy and energy effects on energy poverty. Indirect effects occur through changes in economic growth, trade, and other economy-wide effects. There is a lack of comprehensive or systematic analysis of these impacts of mitigation policies on the poor. Such policies can benefit the poor, although some actions might worsen poverty, hindering its alleviation. A more comprehensive approach must be employed in assessing how policy design and implementation influence these positive and negative impacts on poverty.

Tags: XPRO, XCAU, XHEA

Batterman, S., L. Du, G. Mentz, B. Mukherjee, E. Parker, C. Godwin, J.Y. Chin, A. O’Toole, R. Robins, Z. Rowe, T. and T. Lewis. 2012. "Particulate matter concentrations in residences: an 
intervention study evaluating stand-alone filters and air conditioners." Indoor Air, 22(3): 235252. https://www.ncbi.nlm.nih.gov/pubmed/22145709.

This randomized, controlled trial evaluated 126 low-income households of children with asthma for the effectiveness of free-standing air filters and window air-conditioning units. Three groups were randomly selected, consisting of a control group, a group that received a free-standing high-energy particulate air filter to place in the child's sleeping area, and a group of homes receiving a window-mounted air-conditioning unit. Over three to four seasons, indoor air quality was monitored for week-long periods. High concentrations of carbon dioxide and particulate matter (PM) were frequently seen. Filters were seen to reduce PM levels by $50 \%$. Filter use varied between households and declined over time. When pollutants were monitored, filter use dropped from an initial value of $84+/-27 \%$ to $63+/-33 \%$ in subsequent seasons. When households were not visited, average use dropped to $34+/-30 \%$. Filter effectiveness did not vary in homes with central air conditioning or room air conditioning. PM readings increased by about $14 \mathrm{mu} \mathrm{g} / \mathrm{m}^{3}$ due to environmental tobacco smoke. This was often detected using environmental tobacco smoke-specific tracers despite caregivers reporting household restrictions on smoking. PM levels depended on filter use, air exchange rates, outdoor PM levels, the presence of a central air conditioning, the number of children, relative humidity, sweeping/dusting, and season. If air filters are used, they can provide substantial reductions in PM concentrations. Therefore, strategies must be implemented to encourage use and maintenance of the filters.

Tags: XBES, XTEC, XHEA

Bednar, D. J., et al. 2017. "The intersection of energy and justice: Modeling the spatial, racial/ethnic and socioeconomic patterns of urban residential heating consumption and efficiency in Detroit, Michigan.” Energy and Buildings, 143: 25-34. https://doi.org/10.1016/j.enbuild.2017.03.028.

The inability to identify and distinguish between energy-efficient households and highenergy consumers has led to ineffective targeting of residential conservation and energy efficiency programs. Little is known about the racial, spatial, and socioeconomic patterns of urban energy efficiency and consumption. This study uses data from the US Energy Information Administration and the US Census Bureau along with small area stimation techniques and bottom-up modeling to predict energy use intensity and mean annual heating consumption. Results illustrate spatial disparities in energy use intensity and energy consumption. Bivariate analysis show energy use intensity is correlated with racial/ethnic makeup, although no proven statistical relationship exists between race/ethnicity and energy consumption. Energy use intensity correlations exist at -0.28 , 0.24, and 0.16 for percent White, African American, and Hispanic, respectively. Inverse relationships were revealed between income and housing tenure and consumption and efficiency. Higher consumption was exhibited in areas with higher median incomes and homeownership ( 0.26 and 0.56 , respectively). The results of this study provide evidence 
to support energy efficiency program targeting inclusive of the significance of race, ethnicity, class, and place.

Tags: XCHA, XBES, XICT, XPRO

Begay, S. K. 2018. "How Citizen Potawatomi Nation utilizes energy efficiency and renewable energy to address its high energy burden.” The Electricity Journal. 31(6), 16-22. https://doi.org/10.1016/j.tej.2018.07.005.

The vast majority of the more than 14 billion $\mathrm{MWh}$ of renewable energy generation potential of tribal lands has been underdeveloped. Challenges such as securing interconnection and power purchase agreements, persistent poverty, and difficulty accessing capital have hindered energy development. The Citizen Potawatomi Nation addresses its high energy burden by using energy efficiency and renewable energy.

Tags: XCHA, XPRO, XCAU

Begay, S. K. 2018. "Navajo residential solar energy access as a global model." The Electricity Journal. 31(6), 9-15. https://doi.org/10.1016/j.tej.2018.07.003.

This study looks at the Navajo Nation's efforts to use solar photovoltaic systems to provide residential power access for its approximately 34,000 off-grid tribal members. The adopted solution, developed in collaboration with Sandia National Laboratories, could serve as a residential model to provide the energy requirements of the 1.2 billion people lacking electrical residential power worldwide.

Tags: XCHA, XPRO, XSOL, XRUR

Bell, C. J., S. Nadel, and S. Hayes. 2011. “On-Bill Financing for Energy Efficiency Improvements: A Review of Current Program Challenges, Opportunities, and Best Practices." ACEEE Research Report E118. https://aceee.org/research-report/e118.

Several innovative financing programs have emerged over the past several decades in an attempt to reduce the upfront costs for energy efficiency improvements and assisting property owners in achieving greater energy savings in the residential and commercial building sectors. On-bill financing (where households "pay as they save") is uniquely positioned to reduce such initial cost barriers in several building markets, including some that have traditionally been underserved by energy efficiency finance.

This report investigates experience with on-bill financing programs to analyze the key elements of their success as well as items that might have impeded optimal results. Current barriers to adoption are also assessed for on-bill financing from the perspectives of consumers, utilities, and the financial industry. The report also looks into ways to address these barriers and identifies emerging trends in program implementation.

Tags: XPRO 
Berg, Weston, and Ariel Drehobl. 2018. "State-level Strategies for Tackling the Energy Burden: A Review of Policies Extending State- and Ratepayer-funded Energy Efficiency to Low-income Households." 2018 ACEEE Summer Study on Energy Efficiency in Buildings: Making Efficiency Easy and Enticing. https://aceee.org/files/proceedings/2018/index.html\#/paper/event-data/p390.

Previous research has shown that low-income households tend to devote a greater percentage of their incomes to energy bills and are generally less efficient. Low-income households have also been found to spend three times more of their average household income on energy costs. This forces some families to make trade-offs between energy and other necessities. Such households also face issues with participation in low-income programs, including a lack of access to information about energy efficiency programs, difficulty paying upfront costs for efficiency investments, and barriers to engaging multifamily landlords and tenants in efficiency investments. State regulators must encourage utilities to carefully consider and expand the role of such programs for lowincome energy efficiency within their efficiency portfolios. This paper highlights the mix of various strategies undertaken by state energy offices and utility commissions to extend energy efficiency benefits to low-income consumers, including cost effectiveness testing, goal setting, and other practices complementing local and federal efforts to reach disadvantaged households.

\section{Tags: XCAU, XPRO}

Berg, Weston, Seth Nowak, Grace Relf, Shruti Vaidyanathan, Eric Junga, Marianne DiMascio, and Emma Cooper. (2018). "The 2018 State Energy Efficiency Scorecard.” ACEEE Research Report U1808. https://www.aceee.org/research-report/u1808.

The twelfth edition of the ACEEE State Energy Efficiency Scorecard gives a progress report on state energy efficiency policies and programs that save energy and produce environmental and economic benefits. The Scorecard uses data vetted by state energy officials to rank states in six categories - utility programs, transportation, building energy codes, combined heat and power, state initiatives, and appliance standards. The top states in this year's Scorecard were Massachusetts, California, Rhode Island, Vermont, and Connecticut. The most-improved state was New Jersey; other up-and-coming states included Missouri, Colorado, and South Dakota. Energy efficiency is a growing resource in these states and others, with utilities spending more than $\$ 7.9$ billion in 2017 for efficiency programs nationwide and saving 27.3 million MWh of electricity.

Tags:

Berkland, Stephanie, T. A. Pande, and T. M. Moezzi. 2018. "Putting People Back into the Equation: Impacts of Cultural and Demographic Factors on Multifamily Energy Use Patterns." 2018 ACEEE Summer Study on Energy Efficiency in Buildings: Making Efficiency Easy and Enticing. https://aceee.org/files/proceedings/2018/index.html\#/paper/event-data/p392. 
Changing demographics have brought a new focus on understanding energy use and energy efficiency preferences, including how these factors affect efficiency programs. Some of the most vulnerable populations are housed in multifamily properties. They have the least ability to control technical characteristics of their home and are not able to pay high bills. Better understanding of the cultural factors affecting energy use patterns in these homes would provide insight into the future of energy use as multifamily properties become increasingly common.

Tags: XMUL, XCAU

Berry, Chip, Carolyn Hronis, and Maggie Woodward. 2018. “Who's Energy Insecure? You Might be Surprised.” 2018 ACEEE Summer Study on Energy Efficiency in Buildings: Making Efficiency Easy and Enticing. https://aceee.org/files/proceedings/2018/index.html\#/paper/eventdata/p393.

The 2015 Residential Energy Consumption Survey describes the prevalence of energy insecurity. This is when a household faces a challenge paying energy bills or maintaining adequate heating or air conditioning. According to a nationwide study, energy insecurity affects nearly one in three US households. This paper investigates energy insecurity across households of several demographic, structural, and geographic characteristics. While geographic characteristics showed no significant prediction of energy insecurity in this analysis, demographic and structural characteristics were predictive of a household's likelihood of energy insecurity. There is also data on the severity of energy issues, including the time period for which some households might be without heating or air conditioning. The results produced from this research are useful for government and utility program analysis, including the Low-Income Home Energy Assistance Program.

\section{Tags: XCAU}

Bird, Stephen, and Diana Hernandez. 2012. "Policy options for the split incentive: Increasing energy efficiency for low-income renters." Energy Policy, 48: 506-514. https://doi.org/10.1016/j.enpol.2012.05.053.

There exists a lack of appropriate incentives to implement energy efficiency measures, known as the split incentive problem. Low-income tenants in particular tend to allocate significantly more of their household income to energy expenditure than other renters. This problem affects $1.89 \%$ of all energy use in the United States. If effectively addressed, many of the nation's poorest residents could experience a savings of between 4 and 11 billion dollars annually. The paper argues that a carefully designed program of incentives for participants in conjunction with utility-managed on-bill financing has significant potential to solve many of these complications. The research focuses on three kinds of split incentives and five concerns about addressing split-incentive issues (endurance, savings, scale, incentives, and political disfavor). It proposes a policy 
designed to overcome these issues, with a specific focus on low-income tenants in the context of the United States.

Tags: XMUL, XCBA, XPRO

Bollinger, B., K. Gillingham, and T. Tsvetanov. 2016. "The Effect of Group Pricing and Deal Duration on Word-of-Mouth and Durable Good Adoption: The Case of Solarize CT." Working paper. http://environment.yale.edu/gillingham/BollingerGillinghamTsvetanov_SalesDurationGroupBuy s.pdf.

Group pricing is where a lower price is offered to a group of consumers who purchase a product. Such pricing has become popular in part because it might help spread consumer word of mouth (WOM) as consumers are intrinsically driven to speak with other potential consumers. Limited-time pricing is another popular marketing strategy used to spur product demand. However, for products relying on WOM, limiting the duration of the deal might hinder the consumer's ability to share information on the deal before it expires, reducing adoption. This research investigates the effects of group pricing and limited-time price promotions of WOM and solar photovoltaic adoption in the Solarize Connecticut program. The results show that WOM does not operate effectively if promotions are too short and that group pricing does increase WOM for those affected by the deals. In the absence of group pricing, however, WOM continues to operate and actually becomes more effective.

Tags: XPRO, XBES

Booth, S. 2014. "Here Comes the Sun: How Securities Regulations Cast a Shadow on the Growth of Community Solar in the United States." UCLA Law Review, 61(3): 760-811. https://www.uclalawreview.org/pdf/61-3-4.pdf.

Community solar is a program offering any electricity ratepayer the chance to purchase as little as one panel of a local, off-site solar array in exchange for a reduced utility bill for the lifetime of the solar system. This expands the availability of solar energy to those of all socioeconomic levels by removing financial barriers to solar ownership. Inflexible securities regulations continue to pose a threat to the community solar model by imposing expensive and onerous information disclosure requirements and by adding potential liability issues for community solar developers. The proliferation of community solar could still be feasible so long as such projects can qualify for an exemption from these Securities and Exchange Commission requirements. The uniqueness of community solar unfortunately does not easily categorize into any exemptions. Although investors benefit from antifraud provisions, onerous registration and disclosure requirements largely prevent communities from having the opportunity to invest in community solar. Only in coupling securities classification with an exemption from registration requirements can 
federal and state governments protect community investors while safeguarding their rights to solar energy purchases.

Tags: XSOL, XCBA

Borenstein, S., and L. W. Davis. 2012. "The Equity and Efficiency of Two-Part Tariffs in US Natural Gas Markets.” Journal of Law \& Economics, 55(1): 75-128. https://doi.org/10.1086/661958.

Volumetric charges for residential natural gas in the United States are about $30 \%$ higher than the marginal cost of gas on average. This allows gas utilities to cover their fixed infrastructure and operating costs with an inefficient departure from marginal cost pricing. Proposed methods to recover these costs through monthly fees are opposed because of a widespread belief that current rate schedules have desirable distributional consequences. This report uses nationally representative household-level data to show the positive correlation between natural gas consumption and household income. This correlation is surprisingly weak, showing that current rate schedules are only mildly progressive. The report argues that this is in part because poor households tend to have less energy-efficient homes compared with more affluent families. Bill impacts are calculated under several scenarios showing that even a modest energy assistance program would more than offset the impact of tariff rebalancing on most low-income households.

Tags: XCBA, XMUL

Bradshaw, J. L., E. Bou-Zeid, and R. H. Harris. 2014. "Comparing the effectiveness of weatherization treatments for low-income, American, urban housing stocks in different climates." Energy and Buildings, 69: 535-543. https://doi.org/10.1016/j.enbuild.2013.11.035.

This research presents and demonstrates an evaluation method for how the effectiveness of a weatherization treatment varies geographically because of varying climate and housing stock. Using American Housing Survey data, the low-income housing stock is described in six cities representing a range of climatic and geographic areas. These data were then used with the Home Energy Saver model to simulate current energy consumption and predicted savings from a combination of three weatherization methods: installation of attic insulation, envelope air sealing, and installation of a programmable thermostat. These models were then compared with observed savings. Results show greater energy saving potential in colder climates, although the effectiveness of weatherization treatments varies with regional stock and space conditioning equipment. The results and methodology could be used to compare carbon reductions and the costeffectiveness of future weatherization programs.

Tags: XCBA, XCHA, XCAU, XICT, XTEC 
Bradshaw, J. L., Elie Bou-Zeid, and Robert H. Harris. 2016. "Greenhouse gas mitigation benefits and cost-effectiveness of weatherization treatments for low-income, American, urban housing stocks." Energy and Buildings, 128: 911-920. https://doi.org/10.1016/j.enbuild.2016.07.020.

This paper researches the geographic variation of greenhouse gas mitigation benefits and cost-effectiveness of weatherization treatments due to differences in energy production mix, housing stock, and climate. Energy cost savings and greenhouse gas savings are estimated using a treatment cost database and estimations of the residential energy savings from weatherization. Models were produced using a combination of three weatherization treatments: installation of a programmable thermostat, attic insulation, and envelope air sealing. Each was modeled for the low-income housing stock of six urban areas: Orlando, Florida; Seattle, Washington; Detroit, Michigan; Philadelphia, Pennsylvania; Los Angeles-Long Beach, California; and Milwaukee, Wisconsin. Results show that regional effects have a large impact on the cost of weatherization treatments and that housing stocks with substantial electric space conditioning offer greater greenhouse gas and energy cost savings. The research also determines that greenhouse gas prices are small compared with energy cost savings when the cost-effectiveness of weatherization treatments is evaluated and identifies the installation of programmable thermostats to be the most cost-effective treatment. This highlights the importance of thoughtful consideration of weatherization program goals in the selection of cities and regions to prioritize.

\section{Tags: XCBA, XCHA, XICT, XTEC}

Breysse, J., D. E. Jacobs, W. Weber, S. Dixon, C. Kawecki, S. Aceti, and J. Lopez. 2011. "Health Outcomes and Green Renovation of Affordable Housing." Public Health Reports, 126: 64-75. https://www.ncbi.nlm.nih.gov/pubmed/21563714.

This study attempts to determine whether there are health improvements associated with the renovation of low-income housing using healthy and "green" principles. Resident health and building performance baselines were investigated and compared with readings one year after rehabilitation using Enterprise Green Communities specifications, which reduce moisture, mold, pests, and radon; improve ventilation; and use sustainable building products and other healthy housing features. Measurements of health (taken via questionnaire), ventilation, carbon dioxide, and radon were noted. Adults reported significant improvements in overall health, including with asthma and non-asthma respiratory issues. Adults reported similar overall health improvements in their children as well. New ventilation was installed, with fresh air supplied at $70 \%$ of the American Society of Heating, Refrigerating, and Air-Conditioning Engineers standard. Following mitigation, radon was $<2$ picocuries per liter of air and the annual average carbon dioxide level was 982 parts per million. Over the one-year-postrenovation period, energy use was reduced by $45 \%$. The report concludes that all green building standards should include health requirements, and that the collaboration of environmental health, housing, and 
public health professionals might improve quality of life, health, energy conservation, and building operation.

Tags: XCBA, XHEA

Brown, M. A. 2001. "Market failures and barriers as a basis for clean energy policies.” Energy policy, 29(14): 1197-1207. https://doi.org/10.1016/S0301-4215(01)00067-2.

This paper provides compelling evidence that large-scale market failures and barriers prevent consumers in the United States from obtaining energy services at the least possible cost. Assessments of numerous energy policies and programs suggest that public interventions can overcome many of the market obstacles. By articulating these barriers and reviewing the literature on ways of addressing them, this paper provides a strong justification for the policy portfolios that define the "Scenarios for a Clean Energy Future," a study conducted by five national laboratories. These scenarios are described in other papers published in this special issue of Energy Policy.

Tags: XPRO

Brown, M. A., A. Soni, M.V. Lapsa, and K. Southworth. 2020. Low-Income Energy

Affordability: Conclusions from a Literature Review (Oak Ridge, TN: Oak Ridge National Laboratory), ORNL/TM-2019/1150.

This paper examines the persistent problem of high energy burdens among low-income households, based on a review of more than 180 publications that pointed to several promising opportunities to address energy affordability including inclusive solar programs, leveraged health care benefits, and behavioral economics. using an equity and affordability lens. Even after decades of weatherization and bill-payment programs, lowincome households, on average, continue to spend a higher share of their income on electricity and natural gas bills than any other income group. Energy burden for lowincome households is not declining, and it remains persistently high, particularly in the South, in rural America, among minority households, and those with children and elderly residents. On a per household basis, utility companies spend less on energy-efficiency programs for low-income households than for other income groups. In addition, government and utility programs that promote rooftop solar power, electric vehicles, and home energy storage are largely inaccessible to low-income households. Our review identifies promising opportunities to address energy affordability including inclusive solar programs, leveraged health care benefits, behavioral economics, data analytics, advanced information and communication technologies, and grid resiliency. Scalable approaches require linking implementing agencies, programs and policies to tackle the 
complex web of causes and impacts on low-income households with high energy burdens.

Tags: XBES, XCBA, XCHA, XSOL, XCAU, ZMUL, XDAT, XHEA, XICT, XRUR, XGRI, XMAN, XTEC, XPRO

Brown, M. A., and B. K. Sovacool. 2018. "Theorizing the Behavioral Dimension of Energy Consumption: Energy Efficiency and the Value-Action Gap," in Oxford Handbook of Energy and Society, Oxford University Press (eds D. J. Davidson and M. Gross), pp. 201-221. https://www.oxfordhandbooks.com/view/10.1093/oxfordhb/9780190633851.001.0001/oxfordhb9780190633851-e-9.

This chapter focuses on the well-documented misalignment between energy-related behaviors and the personal values of consumers, which has become a major source of angst among policymakers. Despite widespread pro-environmental or green attitudes, consumers frequently purchase nongreen alternatives. The chapter identifies 50 theoretical approaches that can be divided almost equally into two types: (1) those that emphasize beliefs, attitudes, and values and (2) those that also consider contextual factors and social norms. It is helpful to contextualize consumption practices, recognizing that socio-psychological frameworks are most valuable in explaining the value-action gap within the limits of constraints (such as limited liquidity and the lack of local highefficiency supplies) which can be significant in low-income communities. The chapter recommends that research on the value-action gap be expanded beyond the traditional focus on individuals to include decision-making units such as households, boards of directors, commercial buying units, and government procurement groups.

\section{Tags: XBES}

Brown, Marilyn A., and Yu Wang. 2015. Green Savings: How Policies and Market Drive Energy Efficiency. Praeger Press. https://www.abc-clio.com/Praeger/product.aspx?pc=A4272C.

This landmark work lauds the benefits of decreased energy consumption and investigates its relationship to public policy and analyzes its potential billion-dollar benefits to the US economy. It addresses broad questions concerning electricity systems and the economy; documents innovative, energy-efficiency technologies, practices, and policies; estimates the achievable cost-effectiveness and economic impact of energy efficiency in the United States; illustrates a range of promising strategies for expanding green savings; argues for more market intelligence, monitoring, and evaluation so that energy, economic, and climate goals are met; and showcases the policy environments that have enabled energy efficiency to thrive in leading cities, states, and countries around the world.

Tags: XCBA, XTEC, XPRO 
Brown, M. A., S. Zhou, and M. Ahmadi. 2018. "Smart grid governance: An international review of evolving policy issues and innovations.” Wiley Interdisciplinary Reviews: Energy and Environment. https://onlinelibrary.wiley.com/doi/full/10.1002/wene.290.

The electric power systems of many industrialized nations are challenged by the need to accommodate distributed renewable generation, the increasing demands of a digital society, growing threats to infrastructure security, and concerns over global climate disruption. The "smart grid" - with a two-way flow of electricity and information between utilities and consumers - can help address these challenges, but various financial, regulatory, and technical obstacles hinder its rapid deployment. An overview of experiences with smart grids policies in pioneering countries shows that many governments have designed interventions to overcome these barriers and to facilitate grid modernization. Smart grid policies include a new generation of regulations and finance models such as regulatory targets, requirements for data security and privacy, renewable energy credits, and various interconnection tariffs and utility subsidies.

Tags: XTEC, XGRI, XICT

Cabeza, L. F., et al. 2014. "Investigating greenhouse challenge from growing trends of electricity consumption through home appliances in buildings." Renewable \& Sustainable Energy Reviews 36: 188-193. https://doi.org/10.1016/j.rser.2014.04.053.

According to the International Energy Agency, electricity consumption in both residential and service sectors is rapidly increasing because of continued demand for new appliances with new functionality and the increasing contribution to residential electricity use. This research attempts to document trends and drivers of the energy consumption of appliances in the building sector. The resulting trends show a general increase in appliance electricity consumption, as well as that the proliferation of electronics and small household devices has resulted in a disproportionate amount of household electronic appliances, particularly in Organization for Economic Cooperation and Development countries. This trend promises to continually improve the standard of living throughout the developing world. There is also a large expected impact on appliance energy consumption due to the increased affordability of basic equipment such as washing machines and refrigerators. Additionally, it is shown that electric appliances have a larger carbon footprint in countries where electricity production is carbon intensive. Finally, the results reveal that appliances have significant room for improvements in energy efficiency because most appliances to be installed in the near future have yet to be produced.

Tags: XCAU, XPRO

Carley, S., T. P. Evans, M. Graff, and D. M. Konisky. 2018. "A framework for evaluating geographic disparities in energy transition vulnerability." Nature Energy, 3: 621-627. https://www.nature.com/articles/s41560-018-0142-z. 
Decarbonization brings with it added benefits including new technological innovation and reduced greenhouse gas emissions. However, some individuals and communities are increasingly vulnerable to the adverse effects of policies that are helping to facilitate the energy transition, such as price spikes or job displacement. This paper adapts a framework for conceptualizing vulnerability from climate change adaptation to an energy context. Once the dimensions of the framework are constructed, it is used to provide an illustration for the case of the renewable portfolio standard and devise a scoring system to measure vulnerability across US counties. Analysis shows the framework can be a useful tool in the identification of geographical disparities and should be developed further to provide deeper insights into a just transition.

\section{Tags: XDAT, XCHA}

Camprubí, L., D. Malmusi, R. Mehdipanah, L. Palència, A. Molnar, C. Muntaner, and C. Borrell. 2016. "Facade insulation retrofitting policy implementation process and its effects on health equity determinants: A realist review." Energy Policy, 91: 304-314. https://doi.org/10.1016/j.enpol.2016.01.016.

Energy efficiency interventions, such as façade retrofitting, address issues of fuel poverty and cold housing from a structural and long-term perspective. Little is known about the social and political contexts contributing to inequalities in receiving and experiencing health benefits from insulation. Using a realist review methodology, this paper attempts to understand the mechanisms that explain the appearance of variation across different social groups in receiving façade retrofitting interventions and their impact on health determinants. The research considered the four stages of policy implementation: public policy approach, policy, receiving intervention, and impact on health determinants. Evidence shows that specific social groups, including low-income, renters, and the elderly, suffer the most from fuel poverty and experience more barriers to building retrofitting. These barriers include upfront costs, split incentives, lack of control, disruption, and "presentism" thinking. Some housing energy efficiency policies could exacerbate these inequalities. Such policies must specifically aim to tackle fuel poverty or social inequities, be free to users, and target the most affected groups, adapting to their needs.

Tags: XCBA, XCHA, XHEA

Carroll, David, Chisoo Kim, and Colleen Driscoll. 2014. National Weatherization Assistance Program Evaluation: Eligible Population Report, Oak Ridge, TN: Oak Ridge National Laboratory. https://weatherization.ornl.gov/wpcontent/uploads/pdf/WAPRetroEvalFinalReports/ORNL_TM-2014_312.pdf.

This report presents the results of an analysis of the characteristics and energy requirements of low-income households eligible for the Weatherization Assistance Program. The analysis uses data from the Current Population Survey, the American Housing Survey, and the Residential Energy Consumption Survey. This study was 
conducted for the program year 2008, as part of the national evaluation of the Weatherization Assistance Program.

Tags: XCHA, XPRO

Chan, Coreina, Kendall Ernst, and James Newcomb. 2017. "Breaking Ground New Models that Deliver Energy Solutions to Low-Income Customers.” e-Lab. https://rmi.org/wpcontent/uploads/2017/04/eLabLeap_Breaking-Ground-report-2016.pdf.

Low-income customers tend to be unable to access distributed energy resources such as rooftop solar, but new business models are emerging to serve these consumers. These new distributed energy resources business models adapt and evolve to meet the needs of low-income customers, learning from models that have been successful in serving higherincome customers.

Tags: XPRO, XSOL

Chant, Elizabeth, and Frances Huessy. 2018. "Justice For All: Measures of Equity for LowIncome Programs.” 2018 ACEEE Summer Study on Energy Efficiency in Buildings: Making Efficiency Easy and Enticing. https://aceee.org/files/proceedings/2018/index.html\#/paper/eventdata/p394.

Efficiency programs in the United States, paid for in part with low-income customer funds, fail to provide commensurate benefits to those ratepayers. Low-income households will continue to suffer disproportionately from high energy burdens unless the energy industry names and addresses these effects. This paper assesses the effects of efficiency programming decisions on vulnerable populations. The conditions resulting in the inequitable allocation of efficiency program resources are outlined. The authors also detail methods by which programs can be monitored, measured, and improved. Different efficiency programming categories are investigated for ways in which social equity and energy justice are enhanced or undermined. Results suggest different ethical schools of thought can offer valid approaches for an industry-wide evaluation of interests and can be used in the design of more equitable programs.

\section{Tags: XPRO}

Chant, E., R. Schaaf, and T, Ast. 2016. "Swiftly and Massively: Moving 115,000 Units of Multifamily Affordable Housing to Higher Efficiency." 2016 ACEEE Summer Study on Energy Efficiency in Buildings From Components to Systems, From Buildings to Communities. https://aceee.org/files/proceedings/2016/data/papers/2_203.pdf.

Stewards of Affordable Housing for the Future developed The Big Reach to help its members increase the sustainability of their portfolios, reducing utility costs. This program commits all members to lowering water and energy use throughout their portfolios. The experience was used to suggest policy changes to make housing retrofits 
more effective, and its success offers lessons in scalability in this difficult-to-reach market segment.

Tags: XPRO, XMUL

Chen, S. 2012. Prepaid Energy and Low Income Assistance Programs. Prepay Energy Working Group paper. Washington, DC: Distributed Energy Financial Group LLC. http://defgllc.com/publication/prepaid-energy-and-low-income-assistance-programs/.

This paper presents the principle of universal access, along with programs and services designed to help customers who are falling behind on their utility payments. It uses four categories of customer protection: emergency cash assistance; ongoing discounts or credits; negotiated payment plans; and the cost of service. The paper then describes the common challenges associated with low-income assistance programs, including assistance amounts, enrollment, eligibility, declining funding levels, and the delivery and timing of assistance. These assistance models were then applied to a prepay energy service model. The author then contemplates the ways in which the assistance and prepay models could be adapted to provide assistance similar to that available to prepay customers. The research also touches upon how common challenges can be addressed in a prepay service model.

\section{Tags: XPRO, XCHA, XCAU}

Chen, C. F., X. Xu, and J. K. Day. 2017. "Thermal comfort or money saving? Exploring intentions to conserve energy among low-income households in the United States." Energy Research \& Social Science, 26, 61-71. https://www.sciencedirect.com/science/article/pii/S2214629617300099.

Previous research on low-income households provided little consideration of socialpsychological variables. Using the theory of planned behavior, this paper investigates how climate zones, demographics, and a set of social-psychological variables, including bill consciousness, thermal comfort, frugality attitude, and energy concern, influenced the intention to conserve energy in 248 low-income households nationwide. Results show only three theory of planned behavior variables (perceived behavioral control, subjective norms, and attitudes toward energy conservation) had positive effects on conservation intentions. Perceived behavioral control and attitudes toward energy conservation were the strongest predictors when other variables were accounted for. The need for thermal comfort negatively predicted energy conservation intentions, and bill consciousness positively predicted intentions. Climate zones and gender predicted intentions when the model was used without the inclusion of other variables. The results of this study provide important insights on the energy conservation intentions of low-income households, as well as potential barriers, providing useful recommendations for future policy initiatives.

Tags: XPRO, XCHA, XCAU 
Chetty, R. 2015. "Behavioral economics and public policy: A pragmatic perspective." American Economic Review 105(5): 1-33. https://www.aeaweb.org/articles?id=10.1257/aer.p20151108.

This paper provides a pragmatic perspective on behavioral economics, focusing on its value for improving policy decisions and empirical predictions. Three ways in which behavioral economics can contribute to public policy are discussed: by generating new welfare implications, improving predictions about the effects of existing policies, and offering new policy tools. These contributions are illustrated using applications to neighborhood choice, labor supply, and retirement savings. Behavioral models provide new counterfactuals to estimate the effects of policies, as well as tools to change behaviors. The paper concludes that the incorporation of behavioral features might be more productive than viewing behavioral economics as a separate subfield that challenges the assumptions of neoclassical models.

\section{Tags: XBES}

Clean Energy Advisory Council (CEAC). 2017. Report on Alternative Approaches to Providing Low and Moderate Income (LMI) Clean Energy Services. LMI Clean Energy Initiatives Working Group. file:///C:/Users/f67/Downloads/\%7BB56F124C-0EB9-417B-988674F640EC36A9\%7D.pdf.

The Low and Moderate Income (LMI) Clean Energy Initiatives Working Group was assigned to investigate and evaluate alternatives to the current delivery of rate payerfunded clean energy services to LMI customers. The goal of the project was to add value to the customers served, as well as to the rate-payer funds being invested. The Working Group evaluated the current approaches for delivering clean energy services including energy efficiency, bill reduction and renewable energy; outlined best practice approaches for delivering LMI clean energy services; identified approaches deployed in other jurisdictions; and made recommendations for improving the delivery of services to LMI customers.

Further steps are necessary in order to improve the overall services' delivery to LMI customers to drive access to clean energy solutions and energy affordability. Resources are insufficient, compared to the size of the LMI market, to increase the number of customers that receive services annually. A single approach to improving the delivery of services is insufficient, due to the complexity of the LMI market. It is recommended that the NYSERDA and the utilities take a holistic approach in order to improve clean energy delivery services and coordinate and leverage all the resources that are available, like ratepayer-funded initiatives. The report describes 43 recommendations from the Working Group to NYSERDA, the utilities, and the Public Service Commission to improve clean energy delivery services to LMI customers.

Tags: XPRO 
Cluett, Rachel, et al. 2016. "Building Better Energy Efficiency Programs for Low-Income Households.” ACEEE Research Report A1601. https://aceee.org/research-report/a1601.

There is a need for more equitable spending on efficiency programs designed for lowincome households. This report addresses the challenges and key questions around lowincome programs for single-family homes. Drawing from a range of programs, the report recommends ways to increase the savings and reach of such efficiency programming. Practices to overcome challenges are detailed, and strategies to use underused technologies to realize greater savings are explored.

Tags: XPRO, XTEC

Colton, R. D. 2011. "Home Energy Affordability in New York: The Affordability Gap (2008 2010)." Prepared for New York State Energy Research Development Authority Albany, New York. http://www.nyserda.ny.gov///media/Files/EDPPP/LIFE/Resources/2008-2010affordability-gap.pdf.

In addition to threatening access to energy services, home energy costs in New York households threaten access to food, medical care, housing, and other necessities of life. Home energy unaffordability appears statewide and affects both rural and urban areas. This paper attempts to quantify the extent of this phenomenon, measuring the dollar amount by which actual home energy bills exceed affordable amounts. "Affordability" is investigated in terms of energy burdens and bills as a percentage of household income. An affordable burden is set at 6\%.

Tags: XDAT, XRUR

Cook, Jeffrey J., and Lori Bird. 2018. "Unlocking Solar for Low- and Moderate-Income Residents: A Matrix of Financing Options by Resident, Provider, and Housing Type.” National Renewable Energy Laboratory. hhttps://www.osti.gov/biblio/1416133.

The low-and-moderate-income market has historically been underserved by solar photovoltaics, due in part to the unique barriers to entry faced by low-and-moderateincome residents. low-and-moderate-income residents often have lower credit scores, rent, and have limited funds for the upfront investments required for solar photovoltaics. The applicability and effectiveness of financing strategies adopted by states can vary, depending on homeownership status and housing type. This report attempts to identify promising strategies to be considered to finance photovoltaics for low-and-moderateincome customers in manufactured, single-family, and multifamily housing. Thirteen financing options are explored, each with different impacts related to LMI market deployment and state administration.

Tags: XCBA, XSOL, XMULT 
Cook, Jeffery, and Manisha Shah. 2018. Reducing Energy Burden with Solar: Colorado's Strategy and Roadmap for States. NREL/TP-6A20-70965. Golden, CO: National Renewable Energy Laboratory. https://www.osti.gov/biblio/1431421.

The Colorado Energy Office plans to reduce energy burden for low-income residents through the development of solar photovoltaics. By the end of 2019, approximately 20 MW of photovoltaics will be deployed in the state for low-income households. This report outlines the Colorado Energy Office strategy, including why and how it was implemented and the lessons learned in the process. The strategy aims to support lowincome community solar demonstration projects, incorporate photovoltaics into weatherization programs, and promote utility investment in photovoltaic programs for low-income communities.

Tags: XSOL, XPRO

Cook, J. J., and M. R. Shah. 2018. Focusing the Sun: State Considerations for Designing Community Solar Policy. NREL/TP-6A20-70663. Golden, CO: National Renewable Energy Laboratory. See URL for the full Executive Summary: https://www.nrel.gov/docs/fy18osti/70663.pdf.

This report summarizes outcomes from the State Best Practices Group of the National Community Solar Partnership by identifying key differences in state policies enabling community solar projects and the market impact of various policy decisions. The authors conducted interviews with 19 experts, including utilities staff, regulators, and project developers, to understand the effects of policy design approaches on community solar markets. These perspectives were synthesized to identify key design considerations for community solar programs.

\section{Tags: XSOL, XPRO}

Cook, Ryan. 2014. "Solarize America: how policy networks adopt and adapt good ideas." DSpace@MIT._https://dspace.mit.edu/handle/1721.1/90198.

This paper investigates the role of networks in the production and implementation of clean energy policy ideas through the case of Solarize, a community solar program. The strategies of civic, private, and public policy actors in the Pacific Northwest and in New England are compared. In the Pacific Northwest, community organizations have implemented a grassroots approach to Solarize, compared with New England, where it is primarily government led. Networks vary greatly across contexts, and ideas successful in one local network might be unsuccessful in another without modification. Adopting new ideas includes taking into account differences in resource availability and institutional capacity by redefining relationships and adopting policies to suit local needs. Establishing strong cross-sectional ties, consciously learning from policy successes elsewhere, and 
being flexible in relationships with civic and private actors improves a network's ability to support innovation.

Tags: XPRO, XSOL

Coombs, K., D. Taft, D. V. Ward, B. J. Green, G. L. Chew, B. Shamsaei, J. Meller, R. Indugula, and T. Reponen. 2018. "Variability of indoor fungal microbiome of green and non-green lowincome homes in Cincinnati, Ohio." Science of the Total Environment, 610: 212-218. https://www.ncbi.nlm.nih.gov/pubmed/28803198.

This study aims to investigate the indoor environment of green homes along with the respiratory health of asthmatic children. The microbiome in floor dust, bed dust, and air was compared between nongreen (control) and green (study site) low-income homes in Cincinnati, Ohio. Samples were collected at a baseline time of 4 months after renovation, as well as 12 months after the baseline at the study site. The same sample collection was done in nongreen control homes. These samples were collected over 5 days using PM2.5 samplers. After sampling, bed and floor dust samples were vacuumed and DNA samples were analyzed. There was no clear trend identified in the fungal communities between nongreen and green homes. The differences were instead clearest between sample types (i.e., floor, air, and bed). Microbial communities also largely varied between intervals in both types of homes for all sample types. This could indicate a lack of stability in the microbiomes. Longer follow-up periods might clarify the relationship between microbial load and green renovation of buildings. Research gaps remain regarding the fluctuation of indoor microbiomes over time.

Tags: XCBA, XCAU, XHEA

Corso, Abigail, et al. 2017. "Segmenting Chicago Multifamily Housing to Improve Energy Efficiency Programs.” Elevate Energy. http://www.elevateenergy.org/wp/wpcontent/uploads/Chicago-Multifamily-Segmentation.pdf.

Mitigation efforts in the United States must focus on buildings, given they produce the most emissions and use the most energy of any sector, including transportation. In particular, multifamily buildings, which make up roughly $25 \%$ of US households, require attention. This sector has seen limited success with utility- and government-run efficiency programs in the past. This results in more than 16 million households paying more than necessary to heat and cool their homes.

Tags: XPRO, XMUL

Coughlin, G., J. Irvine, and P. Johnson. 2013. “Guide to Community Solar: Utility, Private, and Non-profit Project Development." Transmission and Distribution World. 
https://www.tdworld.com/generation-renewables/guide-community-solar-utility-private-andnon-profit-project-development.

Community solar projects are becoming more feasible with advances in technology, new financing models, and increases in state and federal incentives. This report is designed to be a resource for those considering implementation of future community solar projects. By exploring a range of policies and incentives and providing examples of successful programs, this paper attempts to guide communities in successfully implementing local energy projects. This guide also suggests changes in the regulatory landscape to boost community solar installations nationwide.

Tags: XSOL, XPRO, XTEC

Craig, C. A. 2016. "Energy consumption, energy efficiency, and consumer perceptions: A case study for the Southeast United States." Applied Energy, 165: 660-669. https://www.sciencedirect.com/science/article/abs/pii/S0306261915016426.

This study examines the relationship between residential electricity consumption and climate variability in the Southeast United States. A survey was conducted with residential electricity providers to understand how best to promote positive behaviors related to energy efficiency in households. The results show that $16.8 \%$ of the variability in residential electricity consumption for heating is explained by indirect costs of energy efficiency. For cooling applications, $36.6 \%$ of the variability was explained by cooling degree days and indirect energy efficiency costs. Analyzing a survey of 2,450 residential consumers using the theory of planned behavior suggests that residents who are aware of utility energy efficiency programs are more likely to participate, support clean energy use by utilities, support government energy efficiency subsidies, and view utility companies more favorably.

Tags: XBES, XCBA

Curti, Julie, Farrah Andersen, and Kathryn Wright. 2018. A Guidebook on Equitable Clean Energy Program Design for Local Governments and Partners. The Cadmus Group. https://cadmusgroup.com/papers-reports/a-guidebook-on-equitable-clean-energy-programdesign-for-local-governments-and-partners/.

Approaching equity intentionally allows municipalities and their partners to create programs prioritizing the accessibility and benefit of clean energy technology for lowand moderate-income households, indigenous communities, and communities of color. This report serves as a guide, introducing a process and principles that can aid in the design of equitable clean energy programs. This project, supported by the Urban Sustainability Directors Network Innovation Fund, intends to develop actionable resources for local governments to advance social equity in the design and implementation of community clean energy programs. An inventory of best practice programs and four case studies is also produced. The project involved seven core Urban 
Sustainability Directors Network cities from the United States and Canada, as well as an Equity Advisory Committee composed of eight representatives serving to ground the research with their work or lived experiences.

Tags: XPRO, XRUR, XTEC

De Silva, D. G., R. P. McComb, and A. R. Schiller. 2016. "What Blows in with the Wind?" Southern Economic Journal 82(3): 826-858. https://doi.org/10.1002/soej.12110.

Shifting toward renewable energy generation methods has clear implications for the spatial distribution of generation plants. Traditional generation plants are often located near population centers, whereas in the case of wind and solar energy, the generation must be located where the energy source is found. This has resulted in the development of wind generation in primarily rural areas. This report looks into the county-level economic impacts of the rapid rise of wind power capacity in Texas. Traditional econometric methods are used to estimate net localized effects in terms of property tax base, employment, personal income, and levels of key public-school expenditure. Results show a significant increase in per capita income accompanying the development of wind power, while employment impacts are modest. County and school property tax rolls realize important benefits from the local development of utility-scale wind power generation, although Texas school funding peculiarities shift localized property tax benefits to the state level.

Tags: XCHA, XCBA, XBES

Doll, S. C., E. L. Davison, and B. R. Painting. 2016. "Weatherization impacts and baseline indoor environmental quality in low income single-family homes." Building and Environment 107: 181-190. https://doi.org/10.1016/j.buildenv.2016.06.021.

In the fields of building science and public health, understanding the relationship between indoor environmental quality and the implementation of energy efficiency measures is key. This study uses data from three North Carolina locations for $\mathrm{NO}_{2}, \mathrm{CO}, \mathrm{CO}_{2}, \mathrm{RH}$, formaldehyde, PM2.5, PM10, radon, temperature, particle counts, weather, and household characteristics in 69 homes, both before and after weatherization (postweatherization), as well as in 13 control homes. A comparison of indoor environmental quality data with indoor and ambient air guidelines showed the number of homes with acceptable indoor environmental quality remained the same or increased after weatherization for all measurements except temperature-and PM in smoking homes. Postweatherization compliance was measured to be more than $90 \%$ for $\mathrm{NO}_{2}$, radon, $\mathrm{CO}$, and $\mathrm{CO}_{2}$ in all homes, and $\mathrm{PM}$ and $\mathrm{RH}$ in nonsmoking homes. The postweatherization level for formaldehyde was $75 \%$ overall and 6\%, 78\%, and 24\% for PM2.5, RH, and PM10, respectively, in smoking homes. At a significance level of $<0.05$, Wilcoxon test results showed that postweatherization levels decreased for radon in heating season homes, $\mathrm{RH}$ in heating season homes without pets, $1.0 \mathrm{mu} \mathrm{m}$ and $2.5 \mathrm{mu} \mathrm{m}$ particles in homes without pets, and an increase in formaldehyde levels in cooling season homes 
without pets. Results also showed particles $>1.0 \mathrm{mu} \mathrm{m}$ and PM10 in heating season homes with pets, and $10 \mathrm{mu} \mathrm{m}$ in cooling season homes. Using Chi-Square analysis identified relationships between season and formaldehyde, $\mathrm{NO}_{2}$, and $\mathrm{CO}$. Results also identified positive correlations between pets and particles $>1.0 \mathrm{mu}$, heating season and increasing formaldehyde levels, smokers and $0.3 \mathrm{mu} \mathrm{m}$ and $0.5 \mathrm{mu} \mathrm{m}$ particles, and negative correlation for $\mathrm{CO}_{2}$ and ventilation.

Tags: XCHA, XCAU, XPRO, XHEA, XDAT

Donovan, Christine, Adam Sherman, Jennifer Wallace-Brodeur, Kristen Scobie, Neil and Louise Tillotson, and Barbara Wyckoff. 2018. "Empowering Those with High Energy Burdens - While Increasing Local Wealth in the North Country." 2018 ACEEE Summer Study on Energy Efficiency in Buildings: Making Efficiency Easy and Enticing. https://aceee.org/files/proceedings/2018/index.html\#/paper/event-data/p395.

This study investigates how those with fixed or limited incomes in the North County of New Hampshire often make difficult choices between energy and other necessities of life such as medicine, transportation, housing, and food. There is an urgent need to reduce energy use and costs as between an estimated 5\% and 50\% of household incomes are used to pay for energy and transportation costs. In 2017, a team of energy efficiency conveners and program implementers was selected to use the nationally recognized Wealth Works Value Chain approach in efforts to show how increasing energy efficiency might enable economic development, community engagement, and social change. The team's purpose was to identify energy efficiency barriers in the region, designing and implementing systems-level solutions in an effort to increase local wealth and workforce development opportunities while enhancing and expanding energy efficiency and weatherization programs. This paper discusses methods for increasing prosperity, stimulating economic development, and creating livable-wage jobs by expanding and deepening local initiatives and collaborations. This paper shares results from the first year of this initiative, exploring new approaches that can be applied to rural areas across the United States.

\section{Tags: XPRO, XCBA, XBES, XRUR}

Donovan, C., S. Bleything, and S. Enterline. 2014. "Increasing Energy Efficiency in Buildings through Smart-Grid Enabled Residential Programs.” 2014 ACEEE Summer Study on Energy Efficiency in Buildings The Next Generation: Reaching for High Energy Savings. https://aceee.org/files/proceedings/2014/data/papers/2-221.pdf\#page=1.

Two pilot programs in Vermont are investigating the role of variable peak pricing, energy-efficient coaching through proactive customer service, web presentment of energy savings information, automated metering infrastructure, and in-home displays on reducing energy use in residential buildings. One pilot is a consumer behavior study that began in 2011 and ended in 2014. This was accompanied by a companion pilot that focused on residential low-income customers between 2012 and 2013. This paper reports the consumer behavior study, focusing on explaining the use of proactive marketing, web 
presentment, hourly energy information, and variable peak pricing to increase conservation-based behavior and energy efficiency in residential buildings. The report presents key findings along with lessons learned and discusses implications for future residential energy efficiency programs.

\section{Tags: XGRI, XPRO, XBES, XICT}

Drehobl, Ariel, and Fernando Castro-Alvarez. 2017. "Low-Income Energy Efficiency Programs: A Baseline Assessment of Programs Serving the 51 Largest Cities." An ACEEE White Paper. https://aceee.org/white-paper/low-income-ee-baseline.

This paper presents a summary of an ACEEE baseline assessment of natural gas and electric energy efficiency programs targeting low-income households located in the largest metropolitan statistical areas in the United States. More than 70 natural gas and electric utilities were surveyed on their 2015 low-income program expenditure, customer participation, energy savings, and best practices. The majority of surveyed utilities do provide low-income programs, although the offerings vary greatly in terms of delivery, design, spending, and savings.

\section{Tags: XPRO, XCBA}

Drehobl, A., M. Chikumbo, and K. Tanabe. 2018. Reducing Energy Waste through Municipally Led Behavior Change Programs. ACEEE Research Report U1810. https://aceee.org/researchreport/u1810.

This study analyzes 50 behavior change programs offered by 40 local governments in 18 states in Canada. The report provides an overview of the goals, design, implementation, and impacts of locally led programs. Detailed information is also provided on numerous program examples, and recommendations are made to aid in the development of future locally led programs.

Tags: XBES, XPRO

Drehobl, Ariel, and Lauren Ross. 2016. "Lifting the High Energy Burden in America's Largest Cities: How Energy Efficiency Can Improve Low Income and Underserved Communities." American Council for an Energy-Efficient Economy. https://aceee.org/research-report/u1602.

This report measures the energy burden of households in 48 of the largest cities in the United States. Results show that low-income, Latino, low-income multifamily, AfricanAmerican, and renter households spend a greater portion of their household income on utilities than the average family. Energy efficiency is identified to be an underused strategy that could potentially reduce energy burdens by up to $30 \%$. Policies and programs are discussed to increase investments in energy efficiency in underserved and low-income communities.

Tags: XPRO, XCHA 
Dryden, A., J. Tisinger, A. K. Lamb, and M. Kent. 2018. "Bringing Together Climate Equity, Health and Energy Efficiency for Low Income Communities.” 2018 ACEEE Summer Study on Energy Efficiency in Buildings: Making Efficiency Easy and Enticing. https://aceee.org/files/proceedings/2018/index.html\#/paper/event-data/p396.

There is a large opportunity to use cap and trade funding in California to design programs with greater ties between health, equity, and energy efficiency. Climate and public health studies reveal that low-income communities are the most vulnerable to health impacts resulting from climate change. Energy efficiency and solar programs must engage public health professionals as well as energy efficiency professionals to ensure health benefits accrue to the most vulnerable. By engaging these professionals, low-income weatherization programs can address the health conditions of both the occupants and the dwelling, while assessing the home for improvements in energy efficiency. This paper assesses the benefits of engaging both public health professionals and energy efficiency contractors to serve vulnerable populations, capture health improvements of efficiency upgrades, and deliver energy efficiency improvements.

\section{Tags: XPRO, XCBA, XHEA}

Eisenberg, Joel. 2014. Weatherization Assistance Program Technical Memorandum Background Data and Statistics on Low-Income Energy Use and Burdens. ORNL/TM-2014/133. Oak Ridge, TN: Oak Ridge National Laboratory. https://info.ornl.gov/sites/publications/Files/Pub49042.pdf.

This technical memorandum intends to provide information useful in understanding the context and purposes of the US Department of Energy's Weatherization Assistance Program, which has been in operation for more than 30 years and is the largest single national residential energy efficiency program. Established by law, its primary purpose is

“...to increase the energy efficiency of dwellings owned or occupied by low-income persons, reduce their total residential energy expenditures, and improve their health and safety, especially low-income persons who are particularly vulnerable such as the elderly, the handicapped, and children." (Footnote: Title 42 of the U.S. Code, Chapter 81, Subchapter III, Part A, 6861.

The statistics and data presented provide reasonable estimates of important low-income housing and energy usage characteristics. The accompanying appendices expand on the sources and methods used to develop these statistics.

Tags: XPRO

Elnakat, A., et al. 2016. "A zip code study of socioeconomic, demographic, and household gendered influence on the residential energy sector.” Energy Reports 2: 21-27.

https://doi.org/10.1016/j.egyr.2016.01.003. 
This report investigates demographic and socioeconomic characteristics on patterns of residential energy use at the ZIP code level in San Antonio, Bexar County, Texas. Variables include median income, median age, gender, occupancy, total energy, per capita energy, per-home energy, population density, and educational attainment. Statistically significant relationships are identified in support of policy development to ensure cost-effective long-term energy management.

Tags: XCHA, XCBA, XCAU, XSOL

Elsawaf, N., et al. 2013. "Economic evaluation and calculations of energy savings by upgrading the heating systems in pre manufactured homes.” Energy and Buildings, 59: 187-193. https://doi.org/10.1016/j.enbuild.2012.12.036.

This paper evaluates energy consumption in low-income houses during heating seasons, estimating savings from upgrades to heating systems. The effectiveness of air-source heat pumps used for space heating is tested using data from eastern North Carolina. An economic evaluation is then performed based on collected data including actual energy consumption and surveys. Results reveal that the lowest energy consumption and intensity occurs in homes with heat pumps as their primary heat source. When integrated in an electric strip heat system, heat pumps are found to reduce heating cost in lowincome mobile homes by up to $52 \%$ and showed improvement in thermal comfort. Results from analyses of economic sensitivity provide an economic justification for heat pumps because their benefits appear to exceed the installation cost, evidenced by positive net present values, particularly after the second year of installation and throughout the 15year life of the retrofitted heat pumps.

Tags: XCHA, XCAU, XCBA, XMAN

Evens, A. 2015. "The utility of the future and low-income households." The Electricity Journal, 28(10): 43-52. https://www.sciencedirect.com/science/article/pii/S104061901500247X.

Investments in energy efficiency for low-income households reduce costs to utilities and lower rates for all customers as a result. Focusing on low-income communities benefits the utility by increasing on-time payments, reducing expenditures on debt collection and shutoffs, and easing demand on the grid. These lower rates would allow utilities to maintain a competitive edge in a future in which households have energy resources outside of traditional utilities.

Tags: XPRO, XCBA

Fabian, M. P., G. Adamkiewicz, N. K. Stout, M. Sandel, and J. I. Levy. 2014. “A simulation model of building intervention impacts on indoor environmental quality, pediatric asthma, and costs." Journal of Allergy and Clinical Immunology, 133(1): 77-84. 10.1016/j.jaci.2013.06.003. 
This study attempts to evaluate the effects of interventions for indoor environmental quality on pediatric asthma health care use, conducting comparisons between energy savings and intervention and health care costs. A previously developed discrete event simulation model is used to predict the effect of environmental factors, seasonality, medication compliance, and medical history on asthma outcomes and indoor pollutant concentrations in low-income multifamily housing. Health care use and costs were estimated at baseline and subsequent to interventions, comparing health care costs with intervention costs and energy savings. The results show interventions led to 7\% to $12 \%$ reductions in serious asthma events with one- to three-year payback periods. Targeting weatherization effects solely toward tightening a building envelope led to $20 \%$ more serious asthma events. This effect was mitigated by eliminating indoor sources such as gas stoves and smokers and repairing kitchen exhaust fans. The report concludes that the designed pediatric asthma model might be a useful tool for prioritizing bundled and individual building interventions based on effects on costs and health. Tradeoffs between indoor air quality, weatherization, and health are also highlighted. This report serves to increase physician's understanding of the effects home environmental changes could have on their patients' asthma.

Tags: XCBA, XCAU, XTEC, XHEA, XMUL

Fabian, P., G. Adamkiewicz, and J. I. Levy. 2012. "Simulating indoor concentrations of $\mathrm{NO}_{2}$ and PM2.5 in multifamily housing for use in health-based intervention modeling." Indoor Air, 22(1): 12-23. https://www.ncbi.nlm.nih.gov/pmc/articles/PMC3248980/.

Low-income, multifamily housing residents might have a greater exposure to environmental pollutants known to influence asthma. Using CONTAM, a multizone airflow and contaminant transport program, this study aims to simulate concentrations, including PM2.5 and $\mathrm{NO}_{2}$ in a prototype multifamily building. Parameters included building leakiness, unit level, smoking, presence and operability of exhaust fans, and stove use. Regression models were developed to explain variability in CONTAM outputs. A database of 1,000 simulated households was generated with characteristics consistent with Boston public housing developments. These were compared with predicted levels of $\mathrm{PM}$ and $\mathrm{NO}_{2}$ and their correlates with literature. Analysis showed that CONTAM outputs are readily explained by available parameters, although one-compartment box models tend to mischaracterize source contributions and concentrations. The study helps to identify intervention opportunities by quantifying key drivers for indoor concentrations in multifamily housing.

Tags: XCBA, XMUL, XCAU, XHEA, XICT

Fisher Sheehan \& Colton: Public Finance and General Economics. 2013. "Home Energy Affordability Gap." http://homeenergyaffordabilitygap.com/.

In 2003, a model for the "home energy gap" was devised. This is the dollar amount by which actual energy bills exceeded affordable amounts. The model calculates this on a 
county level for the entire United States. It has become an invaluable tool for legislative analysis, program-planning, and research. The second "Series of the Affordability Gap" analysis was released in May 2013, bringing with it several improvements.

Tags: XCAU, XDAT, XICT

Fowlie, Meredith, Michael Greenstone, and Catherine Wolfram. 2015. "Are the non-monetary costs of energy efficiency investments large? Understanding low take-up of a free energy efficiency program." American Economic Review, 105(5): 201-04.

https://doi.org/10.1257/aer.p20151011.

This report documents the low take-up of an energy efficiency program that is widely expected to be beneficial to residents. Participants receive a substantial home weatherization retrofit with all equipment and installation costs covered by the program. In the control group, less than $1 \%$ of eligible households took up the program, although this rate increased after further efforts were taken to inform households about the program's benefits and lack of monetary costs. The findings from this study are consistent with high nonmonetary costs of energy efficiency investments and program participation.

Tags: XBES, XPRO

Fox, Abby. 2016. "Utility-Administered Low-Income Programs in the Southeast." Southeast Energy Efficiency Alliance. https://www.seealliance.org/wp-content/uploads/Low-IncomeLandscape-Assessment-FINAL.pdf.

This landscape assessment, produced by the Southeast Energy Efficiency Alliance, identifies clear trends and opportunities as the Southeast region moves forward in its pursuit of comprehensive energy efficiency offerings to serve low-income communities.

Tags: XPRO

Franklin, R., and T. Osborne. 2017. "Toward an urban political ecology of energy justice: the case of rooftop solar in Tucson, AZ." Journal of Political Ecology, 24: 1055-1076. https://journals.uair.arizona.edu/index.php/JPE/article/view/22003.

New concerns about the fair distribution of electricity costs are arising because of the rapid growth of rooftop solar in many US cities. Critics argue that rooftop solar benefits all ratepayers and addresses environmental injustice, while utilities say existing rate structures shift costs from solar owners to low-income customers. This article investigates the implications of rooftop energy justice. Using a case study from southern Arizona, urban political ecology is used to analyze debates speaking to three types of justice: recognition, procedural, and distributive. The utility company's cost shift argument is reframed as a strategic narrative by focusing on political economy, power relations, and the materiality of the grid. The report seeks to understand why distributive 
justice is recognized as legitimate while other types are not. It is proposed that urban political ecology might help further energy justice analyses by allowing the understanding of recognition and procedural injustice as systemic products of the material configuration of the grid, regulation, and rate of return.

\section{Tags: XSOL, XCBA, XCHA, XGRI}

Frey, S. E., H. Destaillats, S. Cohn, S. Ahrentzen, and M. P. Fraser. 2015. "The effects of an energy efficiency retrofit on indoor air quality." Indoor Air, 25(2): 210-219. https://www.ncbi.nlm.nih.gov/pubmed/24920242.

In this study, resident health and indoor air quality were evaluated to investigate the impacts of an energy efficiency retrofit in a low-income senior housing apartment complex in Phoenix, Arizona. Data were collected before and after a green energy building renovation. Air quality sampling was accompanied by a questionnaire designed to gauge the general health of residents and characterize their personal habits. Over the long term, indoor formaldehyde levels decreased by a statistically significant margin for the entire study population. Indoor PM levels showed a similar decrease with certain resident subpopulations, namely those who reported smoking who had lived longer at the apartment complex.

\section{Tags: XCBA, XPRO, XMUL, XHEA}

Funkhouser, E., et al. 2015. "Business model innovations for deploying distributed generation: The emerging landscape of community solar in the U.S." Energy Research \& Social Science, 10: 90-101. https://www.sciencedirect.com/science/article/pii/S2214629615300104.

Community solar has emerged as a deployment model for residential photovoltaic systems in light of intensified concerns over impacts on utility revenue and the equity of deployment subsidies. This paper combines four complementary datasets to analyze how market, regulatory, and policy factors impact community solar deployment. A detailed assessment of community solar deployment in the United States is presented, including insights relating to billing models, nameplate capacity, local market and policy drivers, and propensities of off-taker utilities to adopt different types of community solar. Results show that accounting for both policy/regulatory conditions as well as underlying demand is essential to understand the connections between community solar adoption and utility strategy. In addition to satisfying consumer demand for regulatory requirements for renewable energy, it is revealed that utilities are motivated to develop community solar to alleviate losses related to residential solar photovoltaics.

Tags: XSOL, XPRO, XCAU, XBES

Gilleo, A, S. Nowak, and A. Drehobl. 2017. "Making a Difference: Strategies for Successful Low-Income Energy Efficiency Programs.” American Council for an Energy-Efficient Economy. https://aceee.org/research-report/u1713. 
This report provides an in-depth look at low-income energy efficiency programs that are delivering deep savings and achieving high participation. The key elements to success are explored, including a focus on quality control, statewide coordination and partnerships, leveraging diverse funding sources, and targeting program offerings.

\section{Tags: XPRO}

Gillingham, K., and B. Bollinger. 2017. Solarize your community: An evidence-based guide for accelerating the adoption of residential solar. Yale Center for Business and the Environment. https://cbey.yale.edu/research/solarize-your-community-an-evidence-based-guide-foraccelerating-the-adoption-of.

This paper researches different variations of the Solarize CT campaign, designed to increase the adoption of solar energy in 58 towns throughout Connecticut. Researchers from Yale and Duke Universities determined the main factors that affected household solar adoption, including the use of social networks and ideal campaign lengths. The behavioral underpinnings of consumer decision-making were examined in attempts to reveal why people decide to install solar panels, what hinders the decision, and what factors make this decision more likely.

Tags: XSOL, XPRO, XBES

Gillingham, K., R. Newell, and K. Palmer. 2009. "Energy Efficiency Economics and Policy. Resources for the Future. https://media.rff.org/documents/RFF-DP-09-13.pdf.

This report reviews economic concepts affecting consumer decision-making in energy efficiency, examining related literature. An economic perspective of market barriers, behavioral failures, and market failures is provided in an energy efficiency context. The research assesses how these conditions motivate policy intervention in energy-using product markets and examines policy effectiveness and cost. Theory and empirical evidence suggest there is potential for welfare-enhancing energy efficiency policies, although many open questions remain.

\section{Tags: XBES}

Goldberg, Laura, and Anne McKibbin. 2018. "Breakthroughs in Equity and Energy in Illinois." 2018 ACEEE Summer Study on Energy Efficiency in Buildings: Making Efficiency Easy and Enticing. https://aceee.org/files/proceedings/2018/index.html\#/paper/event-data/p406.

This paper discusses ongoing implementation issues being addressed to ensure that the Future Energy Jobs Act lives up to its promises, which include the provisions of dramatically increased energy efficiency investment in Illinois' economically disadvantaged communities. Included are stories of how organizations in economically 
disadvantaged communities are amplifying their voices to ensure Illinois' clean energy future reflects the needs of people within those communities.

Tags: XBES

Graziano, M., and K. Gillingham. 2014. Spatial patterns of solar photovoltaic system adoption: the influence of neighbors and the built environment. Journal of Economic Geography, 15(4), 815-839. https://doi.org/10.1093/jeg/lbu036.

The diffusion of new technologies is frequently mediated through socioeconomic and spatial factors. This article empirically studies the diffusion of residential solar photovoltaic (PV) systems. We identify the spatial patterns of diffusion, which indicate significant clustering of adoptions, using specific data on PV installations in Connecticut. This clustering does not only follow the spatial distribution of population or income. We find that smaller areas influence adoption more than larger urban areas, in a wave-like centrifugal pattern. Our empirical estimation proves a strong relationship between adoption and the number of nearby previously installed PV systems as well as policy variables and built environment. The effect of nearby systems is reduced with time and distance, proposing a spatial neighbor effect conveyed through visibility and social interaction. These results have the potential to simplify the process of diffusion of PV systems and guide stakeholders in the solar market.

Tags: XBES, XSOL

Grevatt, Jim, et al. 2018. "Small Steps in Coordination Equal Leaps and Bounds for Pennsylvania's Underserved Families: Driving Policy Improvements through Collaborative Advocacy." 2018 ACEEE Summer Study on Energy Efficiency in Buildings: Making Efficiency Easy and Enticing. https://aceee.org/files/proceedings/2018/index.html\#/paper/event-data/p399.

Low-income energy efficiency draws a diverse set of stakeholders from a wide range of public interest fields. Since 2014, advocates from the low-income, affordable housing, energy, and environmental communities have cooperated to develop a targeted strategy that drives improvements in low-income energy policy in Pennsylvania. This work draws on the skills, resources, and expertise of multiple disciplines, prioritizing energy efficiency benefits.

\section{Tags: XPRO}

Gupta, A., S. Swarup, A. Marathe, A. Vullikanti, K. Lakkaraju, and J. Letchford. 2018. "Designing Incentives to Maximize the Adoption of Rooftop Solar Technology." In proceedings of the 17th International Conference on Autonomous Agents and MultiAgent Systems. International Foundation for Autonomous Agents and Multiagent Systems. pp. 1950-1952. http://ifaamas.org/Proceedings/aamas2018/pdfs/p1950.pdf. 
Driven by factors including tax breaks and price reductions, rooftop solar technology is seeing increased adoption in many regions. Recent research has shown that peer effects have an important role in the spread of solar adoption. This work extends the previous results of the "influence maximization" literature, which is used to perform "seed set" selection for a data-driven, highly detailed, agent-based model of household rooftop solar adoption.

\section{Tags: XDAT, XBES, XSOL, XICT}

Gupta, A., Z. Hu, A. Marathe, S. Swarup, and A. Vullikanti, A. 2018. "Predictors of Rooftop Solar Adoption in Rural Virginia." The Computational Social Science Conference. Santa Fe: NM. http://people.virginia.edu/ sss7rs/papers/gupta_etal_css2018.pdf.

This paper determines factors influential in the prediction of rooftop solar adoption in rural Virginia by considering a variety of demographic, social, spatial, and structural features of the households. Synthesizing anonymized data from various sources, this research makes collected data usable under one common architecture and provides a geospatial context. Results show that although social network-based features do not influence the likelihood of adoption, demographics and neighborhood-level features do.

\section{Tags: XSOL, XCHA, XBES}

Healy, N., and J. Barry. 2017. "Politicizing energy justice and energy system transitions: Fossil fuel divestment and a 'just transition'." Energy Policy, 108: 451-459. https://www.sciencedirect.com/science/article/abs/pii/S0301421517303683.

This paper attempts to offer an analytically richer and more accurate picture of the (in)justice impacts of energy policy decisions by extending current conceptualizations of energy justice across energy life cycles, from extraction to final use. Two key areas are identified that need greater scrutiny to enact energy justice within a more democratized energy system. First, the research calls for greater recognition of the power dynamics, politics, and political economy of socio-technical energy transition. The paper uses the example of the fossil fuel divestment movement to focus on the under-researched injustices relating to supply-side climate policy decisions and analysis. Second, the paper calls for more systematic addressment of "just transition" and the role of labor in lowcarbon transitions. This focus allows for a more directly political politicizing framing of a just energy transition and energy (in) justice.

Tags: XPRO, XBES

Heeter, J. S., L. A. Bird, E. J. O’Shaughnessy, and S. Koebrich. 2018. Design and Implementation of Community Solar Programs for Low-and Moderate-Income Customers. 
NREL/TP-6A20-71652. Golden, CO: National Renewable Energy Laboratory. https://www.nrel.gov/docs/fy19osti/71652.pdf.

Community solar, in which a utility or third-party sells portions of a utility-scale photovoltaic array's power or generation to multiple subscribers, is emerging as a potential model to increase LMI solar access and reduce the LMI energy burden. Subscribers receive a credit on their electricity bill when they pay for a portion of the array. Depending on the program structure, this credit might include payment for the associated renewable energy certificates. Subscriber's payments are either made up-front or as an ongoing monthly financing option. It is reported that $73 \%$ of community solar projects in 2015 operated on an up-front payment scheme, while 17\% had an ongoing payment, and $10 \%$ allowed subscribers to select their preferred option. Subscribers also had the option of taking out a private loan to cover the up-front payment.

\section{Tags: XSOL, XPRO}

Henderson, Philip. 2015. "Program Design Guide: Energy Efficiency Programs in Multifamily Affordable Housing." Joint effort of Natural Resources Defense Council, National Housing Trust, Energy Foundation, and Elevate Energy. https://www.energyefficiencyforall.org/resources/program-design-guide-energy-efficiencyprograms-multifamily-affordable-housing/.

Gas and electric utilities in the United States invest billions annually to help their customers become more energy efficient. This is often by making repairs and improvements to customer's buildings and homes. These investments create healthier, more comfortable houses and offices, improve lives by reducing energy expenses, and improve community building stock. The resulting increase in energy efficiency creates local jobs, produces a better utility system with less pollution, and delivers other public benefits.

\section{Tags: XPRO, XMUL}

Hernández, Diana, and Stephen Bird. 2010. "Energy burden and the need for integrated lowincome housing and energy policy." Poverty \& Public Policy, 2(4): 5-25. http://doi.org/10.2202/1944-2858.1095.

This report demonstrates that energy poverty is more pervasive and results in a greater energy burden for low-income tenants than policymakers might assume. This is investigated using detailed sociological and public health qualitative interview data. A large energy burden is due in part to policy noncoordination, lack of funding, and lack of understanding of the benefits of energy conservation, flexible utility billing, and energy education. By examining the Low-Income Home Energy Assistance Program, utility, housing assistance, and weatherization policies, the researchers suggest a regional 
approach to housing policy and home energy, integrating programs in each area to provide a more coherent policy solution.

\section{Tags: XCAU, XPRO, XDAT}

Hernández, D., Y. Aratani, and Y. Jiang. 2014. Energy insecurity among families with children. National Center for Children in Poverty. http://www.nccp.org/publications/pdf/text_1086.pdf.

Often overlooked, energy insecurity is a pervasive issue for low-income families with children. It reflects the inability to meet basic energy, heating, and cooling needs. Energy insecurity is a multidimensional construct describing the relationship between household energy costs and the structural conditions of housing. It is characterized by three elements: (1) coping energy insecurity-energy-related coping methods that potentially bring negative health consequences and compromise the quality of the home environment, (2) physical energy insecurity - inefficient housing structures, and (3) economic energy insecurity - the disproportionate share of household income allocated to utility expenses.

\section{Tags: XBES, XCBA, XHEA}

Hernández, Diana, Yang Jiang, Daniel Carrión, Douglas Phillips, and Yumiko Aratani. 2016. "Housing hardship and energy insecurity among native-born and immigrant low-income families with children in the United States." Journal of Children and Poverty, 22(2): 77-92. https://doi.org/10.1080/10796126.2016.1148672.

The costs for rent and utilities have rarely been examined concurrently in populationbased studies. Together, they account for the largest share of living costs. This paper conducts a multivariate statistical analysis to demonstrate the relative risk of low-income, renter-occupied households with children experiencing "energy insecurity," "rent burden," or a "double burden" as opposed to no burden. Results show specific groups are disproportionately burdened, in addition to low-income households being more likely to experience these economic hardships in general. For example, native-born AfricanAmericans are the most likely to experience the double burden. Although immigrants are spared from the double burden, they are more likely to experience rental burden. These findings might be due to decisions regarding housing quality in low-income communities, the housing stock available to certain groups because of racial segregation, and homecountry values, including energy conservation and modest living. This paper also identifies policy gaps in benefits related to housing and energy targeting low-income communities.

Tags: XCHA, XCAU, XMUL

Hernández, D., and D. Phillips. 2015. "Benefit or burden? Perceptions of energy efficiency efforts among low-income housing residents in New York City." Energy Research \& Social Science, 8: 52-59. https://www.sciencedirect.com/science/article/pii/S2214629615000535. 
Because of poor energy efficiencies and structural conditions, low-income households face high energy costs. This report presents a mixed-method pilot study exploring the effects of upgrades to the energy efficiency of 20 households in a low-income New York City community. Surveys and interviews were administered to the heads of households of various housing types. Landlords of recently upgraded buildings were also interviewed. Results show energy efficiency upgrades improved health and safety, reduced energy costs, and improved thermal comfort. Participants reported generally positive experiences with the upgrades. Some negative consequences are also indicated, and the results further illustrate that weatherization alone is not enough to address all the issues facing lowincome households. Experiences also differed between low-income homeowners and renters. Larger scale research is required to investigate the long-term effects of energy efficiency upgrades in low-income communities.

Tags: XCBA, XMUL, XHEA

Hirshfield, Shayna, and P. J. Iyer. 2012. "The Community Energy Champions Grant: Building Local Organizational Capacity to Catalyze Community Energy Behavior Change." 2012 ACEEE Summer Study on Energy Efficiency in Buildings Fueling Our Future with Efficiency. https://aceee.org/files/proceedings/2012/data/papers/0193-000205.pdf.

Public funding and policy mechanisms are lagging behind when it comes to recognizing the importance of behavioral programs in the reduction of energy consumption. State governments and utilities have begun supporting pilot behavioral initiatives run by local nonprofit agencies. Public support for behavioral programs still pales in comparison to that for technology-based programs. This is due to the burdens of demonstrating the effectiveness of delivery mechanisms and proving their effectiveness. This research examines an organizational model in which behavioral programs are delivered at a community level to address the effectiveness of delivery mechanisms.

Tags: XPRO, XBES

Hoffman, Ian M. 2017. "Gauging the Impact of Various Definitions of Low- and ModerateIncome Communities on Possible Electricity Savings From Weatherization.” Technical brief. Berkeley, CA: Lawrence Berkeley National Laboratory. https://emp.lbl.gov/sites/default/files/lbnl-1007114.pdf.

In this research, Lawrence Berkeley National Laboratory assesses the implications of energy efficiency efforts at the neighborhood level for communities with LMI households. Using data on housing types, demographics, and savings from low-income retrofits or weatherization efforts, the national laboratory is able to provide rough estimates of electricity savings in several scenarios provided by DOE.

Tags: XCBA, XPRO, XDAT 
Hoffman, Ian, Charles A. Goldman, Sean Murphy, Natalie Mims, Greg Leventis, and Lisa Schwartz. 2018. "The Cost of Saving Electricity Through Energy Efficiency Programs Funded by Utility Customers: 2009-2015." Berkeley, CA: Lawrence Berkeley National Laboratory. http://www.swenergy.org/Data/Sites/1/media/lbnl-cse-report-june-2018.pdf.

Electricity efficiency programs funded by utility customers target all market segments (agriculture, industrial, commercial, residential) and include energy audits, education, technical assistance, and financial incentives. This report analyzes the cost reductions due to energy efficiency programs implemented between 2009 and 2015 and funded by customers of 116 investor-owned utilities in 41 states.

\section{Tags: XPRO, XCBA}

Hosgoer, E., and P. S. Fischbeck. 2015. "Virtual home energy auditing at scale: Predicting residential energy efficiency using publicly available data.” Energy and Buildings, 92: 67-80. https://doi.org/10.1016/j.enbuild.2015.01.037.

This research models and examines the energy efficiencies of 7,091 single-family homes from Gainesville, Florida. Using the Princeton Scorekeeping Method to process monthly utility use along with historical weather data, an iterative regression approach is employed to compute three efficiency parameters: (1) reference temperature at which the house turns on heating/cooling; (2) heating/cooling slope as a function of building insulation and heating/cooling unit efficiency; and (3) base load consumption for appliances that do not change with the weather, including lighting, refrigeration, and water heating. Together these parameters make up the normalized annual consumption. In addition, the parameters are regressed against public data to investigate the extent to which statistical insight for residential efficiency profiling can be extracted. These models are designed to pave a path toward the creation of energy efficiency "reservoir maps" across individual households, reducing the information barrier to the adoption of energy efficiency measures.

\section{Tags: XCHA, XDAT, XICT}

Hummel, H., and H. Lachman. 2018. "What is inclusive financing for energy efficiency, and why are some of the largest states in the country calling for it now?" 2018 ACEEE Summer Study on Energy Efficiency in Buildings: Making Efficiency Easy and Enticing.

The 2018 ACEEE Summer Study was the 20th biennial ACEEE conference on Energy Efficiency in Buildings. This important meeting incldued a diverse group of professionals to debate strategies, programs and cutting-edge technologies, in order to reduce energy use and address climate impacts. This year's Summer Study was focused on innovation and worked with our 2018 theme: "Making Efficiency Easy and Enticing."

Participants included: utility staff; policymakers; builders; architects; insurance and financial professionals involved with buildings; building products, equipment, and 
appliance manufacturers; engineers; clean-tech investors; local, state, and federal agency personnel; building owners and operators; energy researchers; consultants; NGOs; behavioral scientists; and energy efficiency professionals.

\section{Tags: XPRO}

Inam W., D. Strawser, K. K. Afridi, R. J. Ram, and D. J. Perreault. 2015. "Architecture and System Analysis of Microgrids with Peer-to-Peer Electricity Sharing to Create a Marketplace which Enables Energy Access." In proceedings of 9th International Conference on Power Electronics and ECCE Asia. ICPE 2015-ECCE Asia. https://www.researchgate.net/publication/308671416_Architecture_and_System_Analysis_of_M icrogrids_with_Peer-to-

Peer_Electricity_Sharing_to_Create_a_Marketplace_which_Enables_Energy_Access.

This paper describes the creation of an electricity marketplace via the new concept of peer-to-peer electricity sharing. In this marketplace, those capable of affording powergenerating sources can sell energy to those who are unable to afford generating sources or who might have increased electricity requirements during certain periods. This paper describes a power management unit that would enable these microgrids to provide affordable electricity.

\section{Tags: XSOL, XPRO, XTEC, XGRI}

Inskeep D., K. Daniel, and A. Proudlove. 2015. "Solar on Multi-unit buildings.” NC Clean Energy Technology Center.

Many multi-unit buildings in the United States have large, unshaded space ideal for solar water heating systems or rooftop photovoltaics. The combined energy use of building occupants leads to a large building energy load. The installation of rooftop solar results in an economy of scale that might significantly reduce the installation costs compared with several, smaller photovoltaic systems on separate buildings. Solar improves a building's energy performance and could increase property value, reduce exposure to the risks of rising energy costs, and improve a building's attractiveness to tenants or condo owners. When implemented after efficiency retrofits, solar might provide the greatest value to owners and occupants alike.

Tags: XMUL, XSOL, XTEC

Interstate Renewable Energy Council. 2018. "Expanding Solar Access: Pathways for Multifamily Housing.” https://irecusa.org/expanding-solar-access-pathways-for-multifamilyhousing/.

This report acts as a guide, outlining two potential paths to increasing solar access for LMI communities, renters, and multifamily residents: (1)off-site shared solar in which multiple customers receive credits on their utility bills for electricity generated by a 
common system, and (2) on-site shared solar via a system in which multiple tenants can share virtual energy generation credits from a single solar system.

Tags: XPRO, XSOL, XMUL

Interstate Renewable Energy Council. 2016. Shared Renewable Energy for Low-to ModerateIncome Consumers: Policy Guidelines and Model Provisions. LMI Guidelines. https://www.energy.gov/sites/prod/files/2016/04/f30/IREC-LMI-Guidelines-ModelProvisions_FINAL.pdf.

Low-to Moderate-Income (LMI) households stand to benefit the most from energy efficiency measures as they typically spend a higher percentage of household income on energy costs. LMI households face considerable financial barriers such as insufficient credit and lack of access to capital. These barriers prevent the adoption of cost-saving clean energy measures. As a higher proportion of LMI individuals and families live in multifamily or rental housing, they face split incentive or ownership barriers that make energy efficiency measures and on-site renewable energy systems infeasible.

Additionally, LMI customers might be unaware of clean energy programs and financing options because of constraints on resources, language barriers, and lack of internet access. Education and marketing are typically not designed with the needs of LMI customers in mind, and therefore might not be as effective with this audience. Shared renewable energy programs could potentially address these barriers while providing tangible benefits, including new opportunities to create pathways to environmental prosperity.

Tags: XPRO, XMUL, XCHA

Jacobs, D. E., E Ahonen, S. L. Dixon, S. Dorevitch, J. Breysse, J. Smith, A. Evens, D. Dobrez, M. Isaacson, C. Murphy, L. Conroy, and P. Levavi. 2015. "Moving into Green Healthy Housing." Journal of Public Health Management and Practice, 21(4): 345-354. https://www.ncbi.nlm.nih.gov/pubmed/24378632.

This paper compares the self-reported physical and mental health of 803 individuals living in 325 apartments in three Chicago housing developments before and after moving into green, healthy housing. The control group was composed of families in traditionally repaired housing. All participants were low-income, subsidized households in public housing. Housing conditions and physical and mental health improved significantly in the study group compared with both the control group and the treatment group while living in the public housing from which they were moved. The results also showed reductions in hay fever, asthma, headaches, sinusitis, respiratory allergies, and angina. Asthma severity was measured by self-reported disturbed sleep and lost school/work days. Asthma symptoms, sadness, restlessness, child behavior, and nervousness all improved 
significantly. Health care cost savings in Medicaid could not be quantified in this study, requiring future investigations over a longer follow-up period.

Tags: XCBA, XMUL, XHEA

Jacobs, D. E., M. Tobin, L. Targos, D. Clarkson, S. L. Dixon, J. Breysse, P. Pratap, and S. Cali. 2016. "Replacing Windows Reduces Childhood Lead Exposure: Results from a State-Funded Program.” Journal of Public Health Management and Practice, 22(5): 482-491. https://www.ncbi.nlm.nih.gov/pubmed/26910871.

Home improvement and weatherization programs tend to discourage window replacement despite considerable evidence that it improves energy conservation and reduces childhood lead exposure. This paper evaluates a pilot program in which old leadcontaminated windows were replaced with new lead-free, energy-efficient windows. Preand postevaluations were conducted in one urban and one rural jurisdiction covering 96 participants in low-income households. Measurements were taken using visual assessment, dust wipe sampling, and self-reported physical and mental health at baseline and after one year. Results show a 44\%, 88\%, and 98\% reduction in geometric mean lead dust for interior floors, interior sills, and exterior troughs, respectively ( $\mathrm{P}<0.001$ ), when comparing baseline measurements to those taken 1 year later. These levels rose slightly from measurements taken just after intervention, and lead dust declined significantly on troughs and sills in both the rural and urban jurisdictions over this time period. On interior floors, lead dust declined by $25 \%(\mathrm{P}=0.38)$ in the urban area and $58 \%(\mathrm{P}=$ 0.003 ) in the rural area. The measured decline in the urban area did not reach statistical significance. This resulted in a net monetary benefit of $\$ 2,460,378$, and residents reported they were "very satisfied" with the window replacement $(87 \%)$. The report concludes window replacement programs eliminate a major source of childhood lead exposure, increase home market value, reduce energy bills, and create local construction and industrial jobs. Therefore, it is concluded that such programs should see increased funding by local and state governments. In budget climates such as Illinois, where public expenditures have been reduced, it is more important than ever to make wise investments such as lead-safe window replacement.

Tags: XCBA, XPRO, XCAU, XTEC, XRUR

Jafary, M., and L. Shephard. 2018. "Modeling the Determinants of Residential Appliance Electricity Use Single-Family Homes, Homes with Electric Vehicles and Apartments." In proceedings of 2018 IEEE Green Technologies Conference. 119-126. DOI:

10.1109/GreenTech.2018.00030.

This report provides a data-mining-based methodology for setting rules to identify factors determining the electricity consumption of appliances based on data collected over four years from 800 single-family homes and apartments in Austin, Texas. Data were collected from apartments containing multiple families, single-family homes with electric vehicles, and a reference case of single-family homes. Cluster analysis was 
performed on group homes using calculated average hourly appliance electricity use, socioeconomic characteristics of residents, and building attributes. Results indicate appliance electricity consumption is significantly correlated to variables from all three building types. Residents at homes with electric vehicles and at reference homes spent more time at dwellings, increasing appliance electricity consumption. Residents with higher income tend to consume more electricity, and residents with electric vehicles attain a higher education level but do not necessarily show reduced use of appliances. Results of this analysis can provide new tools and insights for policymakers and for the utility sector as programs are deployed to enhance customer service in response to growing demand for distributed generation and to optimize electricity use with existing generation capabilities.

Tags: XBES, XCHA, XTEC, XDAT, XICT

Jaske, M. 2016. Translating Aggregate Energy Efficiency Savings Projections Into Hourly System Impacts. CEC-200-2016-007. California Energy Commission Staff Report. https://www.energy.ca.gov/2016publications/CEC-200-2016-007/CEC-200-2016-007.pdf.

This report describes the translation of energy efficiency savings projections into 8760 hourly profiles of system impacts suitable for use in models for production simulation. Two sets of savings were developed for 2016 through 2026. MidBase-Mid Additional Achievable Energy Efficiency savings from the 2015 Integrated Energy Policy Report were initially translated to 8,760 hourly impacts. Energy efficiency savings projected until 2030 were then developed to estimate the utility-specific and statewide energy savings that the California Energy Commission is required to establish by Senate Bill 350 (De Leon, Chapter 457, Statutes of 2015). Using the method developed for additional achievable energy efficiency in the 2015 Integrated Energy Policy Report, these aggregate savings were then translated into 8,760 hourly system impacts.

\section{Tags: XDAT}

Jenkins, K., D. McCauley, R. Heffron, H. Stephan, and R. Rehner. 2016. "Energy justice: a conceptual review.” Energy Research \& Social Science, 11: 174-182. https://www.sciencedirect.com/science/article/pii/S2214629615300669?via\%3Dihub.

This research conducts a conceptual review for the consolidation and logical extension of the field of energy justice. The report provides an account of its core tenets: procedural, recognition, and distributional. Results promote the application of this approach across the energy system, within the global context of energy consumption and production. Both a conceptual review and a research agenda are produced. The report explores the key aspects of this new agenda, demonstrating that energy justice offers a new framework bridging existing and future research on energy production and consumption, as well as an opportunity to explore where injustices occur and develop new avoidance and remediation processes. The report concludes with suggesting three areas for future 
research: uniting production and consumption systems, engaging economics, and investigating the nonactivist origins of energy justice.

Tags: XBES

Johnson, E., R. Beppler, C. Blackburn, B. Staver, M. Brown, and D. Matisoff. 2017. "Peak shifting and cross-class subsidization: The impacts of solar PV on changes in electricity costs." Energy Policy, 106: 436-444. http://dx.doi.org/10.1016/j.enpol.2017.03.034.

The paper investigates the impact of the expansion of distributed solar panels on both utilities and their customers. Using net metering data from New Jersey, as well as market data and demand profiles from PJM (a regional transmission organization in the United States), the authors studied the rate and bill impacts of large-scale solar penetration. The results showed how electricity rates increase as high-income households increasingly participate in solar net metering programs. Accordingly, such programs result in higher energy burdens for low-income households since they cannot participate in these programs. In addition, the authors illustrated that a significant solar program can result in a $2 \%$ increase in bills for nonparticipants. This happens because high penetration of solar can change the peak hour to the evening when solar production diminishes, and thus residential customers in general (who typically have high levels of demand for electricity in early evening hours) face higher distribution costs.

Tags: XCBA, XCHA, XSOL, XPRO

Keilty, Kristina. 2018. "Washing with Cold Water: Are You Up for the Challenge? A CBSM Strategy for Engaging Low and Moderate Income Populations.” 2018 ACEEE Summer Study on Energy Efficiency in Buildings: Making Efficiency Easy and Enticing. https://aceee.org/files/proceedings/2018/index.html\#/paper/event-data/p402.

The paper studies the impacts of the "Cold Water Wash Challenge" Pilot in Toronto, Canada, funded by Enbridge Gas Distribution and implemented by Summerhill. The program was focused on community-based social marketing to involve low- to moderateincome energy consumers in multi-unit residential buildings on energy efficiency. The goal was to work with tenants on the benefits of participating in this program for their laundry needs in multi-unit residential buildings to reduce natural gas consumption. The success the community-based social marketing implementation and outreach approach resulted in increasing the participation rate by about $20 \%$. A wide range of strategies were considered from marketing in laundry rooms to building outreach events with hired local community representatives, offering laundry detergent samples, and providing financial benefits to motivate residents to participate in the program.

Tags: XPRO, XMUL, XBES

Khan, Haider, and Kevin Duffy. 2018. "Non-Wires Alternatives: A Case Study in an Economically Depressed Location.” 2018 ACEEE Summer Study on Energy Efficiency in 
Buildings: Making Efficiency Easy and Enticing.

https://aceee.org/files/proceedings/2018/index.html\#/paper/event-data/p187.

Non-wires alternatives are types of distribution system planning solutions that provide an opportunity to address the defined system need while postponing, reducing, or eliminating the need to construct new distribution infrastructure and continue to guarantee safety and reliability. A utility company in the Midwest is considering a twoyear non-wires alternatives program to identify the role that distributed energy resources can play in postponing utility distribution system investments. The goal of the program is to use different distributed energy resources to a specific constrained location to provide load relief and defer infrastructure investment. The program was implemented in an economically depressed region, which resulted in a learning experience for the utility. Although the program has faced several challenges, it has resulted in a notable reduction in peak demand.

Tags: XBES, XPRO

Kontokosta, Constantine E., Vincent J. Reina, and Bartosz Bonczak. 2019. Energy Cost Burdens for Low-Income and Minority Households. Journal of the American Planning Association. https://www.tandfonline.com/doi/full/10.1080/01944363.2019.1647446.

Utility costs are one of the three primary components of housing affordability measures (transportation, rent and utilities). They are the least understood and at the same time are the one area where costs can be reduced without household relocation. There are few data sources to estimate energy costs. These are limited to small sample surveys with low spatial and temporal resolution, such as the American Housing Survey and the Residential Energy Consumption Survey. This study presents a new method for smallarea estimates of household energy cost burdens (ECBs). The method leverages actual building energy use data across five U.S. cities for about 13,000 multifamily properties and relates energy costs to savings opportunities by analyzing 3,000 energy audit reports. The study analyses spatial, regional, and building-level variations in energy use and expenditures and examines differentials in cost burdens across household demographic and socioeconomic characteristics. Results show that the ECB for low-income and higher income households are on average $7 \%$ and $2 \%$, respectively. Low-cost energy improvements could reduce energy costs by a maximum of $\$ 1,500$ per year for lower income households.

Tags: XPRO, XBES, XCAU, XMUL

Kraft-Todd, G.T., B. Bollinger, K. Gillingham, S. Lamp, and D.G. Rand. 2018. "Credibilityenhancing displays promote the provision of non-normative public goods." Nature, 563(7730): 245. https://doi.org/10.1038/s41586-018-0647-4.

Big challenges come with the promotion of public goods that are not yet widely accepted mainly because most tools for increasing cooperation are effective for commonly 
practiced or agreed upon as being desirable behaviors. This article examines how advocates can effectively promote unpopular public goods by applying the cultural evolutionary theory of credibility-enhancing displays. This theory claims that actions spread beliefs more effectively than words alone because actions provide information about the actor's true beliefs. A field study of a program, which promotes the installation of residential solar panels in 58 towns in the United States (1.4 million residents) concluded that $62.8 \%$ more residents were recruited by community organizers who themselves installed solar panels through the program than community organizers who did not. This effect was also seen in three randomized survey experiments (total $\mathrm{n}=1,805)$. Results also show that this effect is specifically driven by the subjects' beliefs about the beliefs of the community organizer regarding solar panels (second-order beliefs), and demonstration the connection with four other highly non-normative behaviors. The findings of the study help clarify how to spread non-normative pro-social behaviors, propose an empirical demonstration of displays to improve credibility and have considerable implications for practitioners and policy makers.

Tags: XPRO, XBES, XSOL, XCAU

Kravatz, M. A., E. Belliveau, B. Tonn, and G. Clendenning. 2018. “Co-Funded Health-Focused Housing Intervention Measure Benefits: Establishing a Co-Funded Low-Income Residential Program Model." 2018 ACEEE Summer Study on Energy Efficiency in Buildings: Making Efficiency Easy and Enticing. https://aceee.org/files/proceedings/2018/index.html\#/paper/eventdata/p403.

Recent attempts to reduce costs while improving demand management have resulted in advancements in the healthcare industry. These advancements include a wide range of solutions, from changing revenue generation from a fee-for-service payment system that appreciates increasing demand to a value-based model that cares for outcomes like demand reduction, higher public health rate, and lower health care costs. As a result, the healthcare industry has considered energy efficiency as a means to provide health program administrators "co-funding" opportunities. This paper reviews mutual benefits that both the energy efficiency and healthcare industry can obtain by collaborating with each other.

\section{Tags: XPRO, XBES, XHEA}

Langevin, J., P. L. Gurian, and J. Wen. 2013. "Reducing energy consumption in low income public housing: Interviewing residents about energy behaviors.” Applied Energy, 102: 13581370. https://www.sciencedirect.com/science/article/pii/S0306261912005144.

Low-income housing has been overlooked in terms of its potential for energy reduction. The authors conducted semistructured interviews to learn more about key behavioral tendencies, energy knowledge gaps, and preferences of low-income households. The sampling methods used in this research were also useful in allowing both quantitative and qualitative analysis of behavior responses. The paper shows how emerging themes from 
the response analysis can be used to inform future surveying and intervention efforts. Those themes include the varying definitions for "comfort" amongst residents, lack of control over the household environment, the tendency to evaluate costs/saving/comfort associated with energy conservation measures, muted behavioral differences among those who do and do not pay energy bills, and the importance of building maintenance and energy education for residents.

\section{Tags: XBES}

Leventis, G., C. Kramer, and L. C. Schwartz. 2017. "Energy Efficiency Financing for Low- and Moderate-Income Households: Current State of the Market, Issues, and Opportunities." State and Local Energy Efficiency Action Network (SEE Action). https://www4.eere.energy.gov/seeaction/system/files/documents/LMI-final0914.pdf.

This paper focuses on the use of financing, including loans or products that encourage energy efficiency improvements, as a method of ensuring that low- and moderate-income households have access to energy efficiency. It does so by examining single-family and multifamily energy efficiency financing programs across the United States. For the purposes of this report, a low- and moderate-income household is defined as those making up to three times the federal poverty level.

Tags: XPRO, XBES, XMUL

Leventis, Greg, Emily Martin Fadrhonc, Chris Kramer, and Charles Goldman. 2016. "Current Practices in Efficiency Financing: An Overview for State and Local Governments." Lawrence Berkeley National Laboratory, LBNL-1006406. http://etapublications.lbl.gov/sites/default/files/lbnl-1006406.pdf.

The study examines various debt-based instruments to study energy efficiency financing across state and local governments. The authors aim to provide governments and decision-makers with a typology of financing instruments, an overview of current programs, and decision support identifying the features and merits of these instruments and programs. In particular, the study identifies two types of financial instruments traditional and specialized. Traditional instruments include loans and leases; specialized instruments encompass a broader grouping of products such as on-bill financing, PACE and saving backed arrangements

Tags: XPRO, XCHA, XCAU, XMUL

Lin, J. 2018. “The Pay As You Save program in rural Arkansas: An opportunity for rural distribution cooperative profits." The Electricity Journal 31(6): 33-39. https://emp.lbl.gov/sites/all/files/lbnl-1006406.pdf.

This paper examines how the Ouachita Electric Cooperative's Pay As You Save program has been successful in lowering customer electricity bills and helping implement energy 
efficiency. Specifically, the study looks at the case of the rural areas of Camden, Arkansas. Pay As You Save benefits users with high energy burdens through an on-bill tariff design. Although it is not explicitly billed as a low-income energy assistance program, the program has been successful in bypassing challenges including upfront outlays and split incentives.

Tags: XPRO, XCBA, XRUR

Lin, J. 2018. "Affordability and access in focus: Metrics and tools of relative energy vulnerability." The Electricity Journal 31(6): 23-32. https://doi.org/10.1016/j.tej.2018.06.005.

This paper examines how household budgets can highlight low-income energy vulnerability. The work strives to identify factors and metrics that would best measure how affordable energy is. The result of the paper is an "Ability-to-Pay" index that examines 57 possible indications of low-income vulnerability (through the use of univariate statistical correlations). This includes a corresponding geographic information system map, which provides affordability and vulnerability data for utility companies and other energy stakeholders.

Tags: XCHA, XCBA, XBES

Long, M., P. Zhao, H. Yaptinchay, M. Prado, S. Walmsley, and E. Giarta. 2018 "Data Driven Approaches to Understanding Occupant Natural Gas Use Behavior in Low-Income Multifamily Communities." 2018 ACEEE Summer Study on Energy Efficiency in Buildings: Making Efficiency Easy and Enticing. https://aceee.org/files/proceedings/2018/index.html\#/paper/eventdata/p254.

This paper puts forth a data-driven framework in ongoing projects in two low-income communities. The research examines natural gas use in low-income communities, including space and water heating and cooking, and identifies space heating as the primary load. These loads have unique user behaviors in different demographic groups and are based on whether the landlord or the tenant pays for the energy. The challenges of high change-over rates and the split incentive issue exacerbate this problem as they make it harder to conserve energy and to retrofit appliances. This paper designs a survey instrument based on the theory of behavioral adaptation to determine what elements increase the use of natural gas and can be used to develop a data acquisition system that identifies user segments.

Tags: XMUL, XBES, XCHA

Massetti, Emanuele, Marilyn Brown, Melissa Lapsa, Isha Sharma, James Bradbury, Colin Cunliff, and Yufei Li. 2017. "Environmental Quality and the U.S. Power Sector: Air Quality, Water Quality, Land Use and Environmental Justice.” ORNL/SPR-2016/772. Oak Ridge, TN: Oak Ridge National Laboratory. http://info.ornl.gov/sites/publications/files/Pub60561.pdf. 
This paper examines environmental quality issues pertaining to the generation, transmission, distribution, and consumer use of electricity within the United States. This includes a variety of topics, including nongreenhouse gas air pollution, land use, water pollution, and human and environmental impacts. The work characterizes present-day impacts and recent trends in addition to an overall assessment of what causes change.

Tags: XCAU, XGRI

Monyei, C. G., B. K. Sovacool, M. A. Brown, K. E. Jenkins, S. Viriri, and Y. Li. 2019. “Justice, poverty, and electricity decarbonization." The Electricity Journal, 32(1): 47-51. https://doi.org/10.1016/j.tej.2019.01.005.

This research paper concludes that cheaper electricity does not necessarily follow largescale integration of renewable energy into existing electricity grids. The same is true of economic equity and improved energy security, as evidenced in Germany, California, and Australia. The paper asserts a contrary result that programs designed to reduce chronic poverty can actually be hurt by efforts to integrate renewable energy within existing electrical grids.

Tags: XGRI, XCAU

Nahmens, I., A. Joukar, and R. Cantrell. 2015. "Impact of Low-Income Occupant Behavior on Energy Consumption in Hot-Humid Climates." Journal of Architectural Engineering 21(2). https://doi.org/10.1061/(ASCE)AE.1943-5568.0000162.

Using both quantitative and qualitative approaches, this paper focuses on energy usage patterns of low-income households in hot-humid climates. Both subjective perceptions of low-income occupants and real field data were analyzed to categorize user behavior into nine independent factors, which were then ranked in terms of impact on energy bills. The top five factors were identified as: (1) cooling set point during the summer, (2) energysaving practices/behaviors of households, (3) occupant behavior with respect to indoor environment quality, (4) occupant behavior with respect to lighting and electrical appliances, and (5) heating set point during the winter.

\section{Tags: XCHA, XBES}

Narassimhan, E., and C. Johnson. 2018. "The role of demand-side incentives and charging infrastructure on plug-in electric vehicle adoption: analysis of US States." Environmental Research Letters, 13(7). https://iopscience.iop.org/article/10.1088/1748-9326/aad0f8.

This paper examines the impact of state and local incentives on consumer purchase behavior pertaining to plug-in vehicles. The results, which were based on vehicle purchase data from 2008-2016, were as follow: (1) tax incentives and charging programs had a large impact on consumer behavior; (2) rebates worked better than tax credits; (3) battery electric vehicle purchases were impacted by tax incentives more than those of 
plug-in vehicles; and (4) when the battery-only driving range of a plug-in vehicle increases, the correlation of public charging and vehicle purchases increases, but the opposite is true with regard to battery-only vehicles. The paper concludes with recommendations of early investments in charging infrastructure and tax incentives to increase the battery-only range in both battery-electric and plug-in vehicles.

Tags: XBES, XPRO

National Research Council. 2010. America's Climate Choices: Advancing the Science of Climate Change. Washington, D.C.: National Academies Press. https://www.nap.edu/catalog/12782/advancing-the-science-of-climate-change.

This paper recommends a single federal program to guide a national, multidisciplinary effort to increase both the understanding of and response to climate change. Specifically, the paper identifies decisions made in response to climate change across 12 different sectors and examines 7 research themes to support the proposed federal program. The paper also recommends that efforts in responding to climate change research should increase, including in areas of human capital investment, climate model improvement, comprehensive climate observing systems, and increased links between research and decisions through partnerships with action-oriented programs.

Tags: XPRO

National Research Council. 2010. America's Climate Choices: Adapting to the Impacts of Climate Change. Washington, D.C.: National Academies Press. https://www.nap.edu/catalog/12783/adapting-to-the-impacts-of-climate-change.

This paper calls for a shift away from the present look at climate change issues (e.g., using past data) and, instead, moving towards a forward-looking model. This requires action from decision-makers across the spectrum, including local and tribal as well as federal, private groups, etc. Presently, such efforts are stalled given the lack of information about benefits, costs, and the effectiveness of various adaptation options, as well as a lack of climate information and coordination. The paper recommends a national adaptation that provides technical, scientific resources, as well as incentives, to begin adoption planning, guidance across jurisdictions, shared lessons learned, and support of scientific research to expand knowledge of impacts and adaptation.

Tags: XPRO, XDAT

Niederberger, Anne Arquit. 2018 "Empowering Low-Income Customers to Shop Energy Smart at Scale." 2018 ACEEE Summer Study on Energy Efficiency in Buildings: Making Efficiency Easy and Enticing. https://aceee.org/files/proceedings/2018/index.html\#/paper/event-data/p389.

This paper examines programs in California and New York that focus on incentivizing low-income customers with larger incentives on super-efficient products that would 
reduce their energy bills, avoid energy costs, and reduce the need for subsidy payments funded by ratepayers. Moreover, the paper discusses recent innovations implemented by utilities and retailers that address up-front price barriers, which are also designed to help low-income households. Through the use of data to target marketing to and incentivize low-income households, utility online marketplaces can scale participation and improve the effectiveness of residential programs.

\section{Tags: XBES, XTEC, XPRO}

Nordman, B. and M.C. Sanchez. 2006. "Electronics Come of Age: Taxonomy for Miscellaneous and Low Power Products." 2006 ACEEE Summer Study on Energy Efficiency in Buildings, pp. 9-248-9-259. https://aceee.org/files/proceedings/2006/data/papers/SS06_Pane19_Paper22.pdf.

Most energy end uses are apparently well-defined in what is included and have terminology that derives from the professionals who work in the relevant field. The topic of "miscellaneous" consumption lacks clarity for historical and practical reasons. As interest from the energy community grows so does the confusion and ambiguity around the topic, this is the reason why the barrier to progress is increasing. The paper provides key definitions for important terms and concepts that will allow future works to be correctly reported and interpreted. The research also provides taxonomy of product types and categories which covers both residential and commercial miscellaneous consumption. A vital element is the identification of "electronics" as a distinct energy end use. In conclusion products are identified as to whether they commonly have a low power mode, and product types that have such modes within the traditional end uses are also listed.

\section{Tags: XBES}

Norton, Bryan G. 2005. Sustainability: A Philosophy of Adaptive Ecosystem Management. University of Chicago Press.

https://www.press.uchicago.edu/ucp/books/book/chicago/S/bo3641681.html.

There is a reduced successful integration of science and social values despite the multiple disciplines that contribute to the environmental conversation. Bryan Norton shows how linguistic resources discourage any environmental goal and policy. Norton, consequently, develop a new approach to the definition of sustainability in which he avoids the ideological vocabulary, using philosophical and linguistic analyses. And all of this is made to accommodate scientific and evaluative environmental discourse.

This book provides a practical framework that encourages an experimental approach to language clarification, problem formulation and an interdisciplinary approach to creating solutions. This is done through emphasizing cooperation and adaptation through social learning. Sustainability offers an entirely novel approach to 
environmentalism, by moving beyond the scientific arena to acknowledge the importance of public discourse.

Tags: XBES

O’Dwyer, C. 2017. "Eligibility for Payment Assistance: A Historical Perspective \& A Look Forward." Low Income Energy Issues Forum paper. Washington, DC: Distributed Energy Financial Group LLC.

Given the increase in the number of eligible low-income households and the decrease in the Low-Income Home Energy Assistance Program, there is an increased need for utility companies and state and federal agencies to better understand and define what customers need assistance. To do so, these groups need to acquire better information about their customers and target those who have the greater need.

\section{Tags: XBES, XTEC, XPRO, XCHA}

O’Dwyer, C. B. 2013. "Engaging and Enrolling Low Income Consumers in Demand Side Management Programs.” Low Income Energy Issues Forum paper. Washington, DC:

Distributed Energy Financial Group LLC. http://defgllc.com/publication/engaging-andenrolling-low-income-consumers-in-demand-side-management-programs/.

This paper creates a new marketing model for low-income consumers, given the tight budgets of low-income users and the lack of knowledge of the specific needs of these customers, which come together to make traditional marketing methods unsuccessful. This new model centers on four distinct but complementary approaches: (1) a marketing and outreach approach that relies on trust; (2) a behavioral change approach that focuses on the consumer experience; (3) a partnership approach that employs strong communication, a well-defined process, leveraging of funds, and tracking of results; and (4) a transactional approach that creates interaction based on information that consumers can use to create a better customer experience.

Tags: XCHA, XBES, XPRO

Padhee, M., and A. Pal. 2018. "Effect of Solar PV Penetration on Residential Energy Consumption Pattern." In 2018 North American Power Symposium (NAPS) IEEE. pp. 1-6. https://ieeexplore.ieee.org/document/8600657.

This paper examines residential rooftop penetration in the United States, building on the model previously designed by the authors (a bottom-up approach for computing seasonwise household-level residential energy consumption profiles using a synthetic population resource). The newer model accounts for the impact of increased rooftop solar penetration on residential energy demands within different regions. This information can, 
in turn, help electric power utilities in managing the increased numbers of residential rooftop solar installations within their service area.

Tags: XSOL, XCHA

Paulos, Bentham. 2017. Bringing the Benefits of Solar Energy to Low-Income Consumers A Guide for States \& Municipalities. PaulosAnalysis. https://www.cesa.org/assets/2017Files/Bringing-the-Benefits-of-Solar-to-Low-Income-Consumers.pdf.

This paper examines the Sustainable Solar Education Project, one of six programs produced by the Clean Energy States Alliance. This specific program seeks to disseminate information and educational resources to help states and local governments in the area of distributed solar energy, namely, that the benefits of solar energy are accessible to low- and moderate-income households and that the energy remains consumer friendly. As part of this initiative, the project produces and provides resources aimed at consumers, including webinars, online courses, and in-person trainings on various topics pertaining to solar energy.

Tags: XPRO, XSOL

Porse, Erik, Joshua Derenski, Hannah Gustafson, Zoe Elizabeth, and Stephanie Pincetl. 2016. "Structural, geographic, and social factors in urban building energy use: Analysis of aggregated account-level consumption data in a megacity." Energy Policy 96: 179-192. https://www.sciencedirect.com/science/article/abs/pii/S0301421516302853?via\%3Dihub.

This paper examines aggregated account-level utility billing data for energy consumption over two million properties in Los Angeles County, given the varied incomes of the owners, geographies, and even climates. The research found that energy use profiles also varied: several higher-income areas have greater total energy use per building even in cooler climates, while many lower-income regions rank higher for energy use per square foot. Energy consumption also correlates with building age, which varies widely throughout the region. The paper notes that while billing data is critical for devising realistic and practical energy efficiency programs, opening access to such data presents significant challenges for protecting personal privacy. Thus, an approach is recommended that is adaptable and scalable to cities seeking to develop data-driven policies to reduce building energy use.

Tags: XCHA, XCAU, XPRO

Power, Meg. 2008. "Fuel Poverty in the USA: The Overview and the Outlook." Energy Action, Issue No. 98, March. http://www.opportunitystudies.org/wp-content/uploads/2011/11/fuelpoverty.pdf.

The article shows an overview of fuel poverty in the USA. It states that there is a considerable difference between focused nature of UK fuel poverty policy and the scattering of US national and state policies that are targeted at low-income energy 
consumers. The difference is described by fuel poverty analyst Meg Power as "focus envy". The overview includes: the kaleidoscope of US policy; US fuel poverty based on UK indicators; fuel poverty in the united states; energy factors; subsidies; housing and (in)efficiency; and the long view. U.S. advocates for a universal service obligation that foresees a policy that guarantees consumers access to energy services for safety, sanitation and basic needs in return for regular affordable payments. Current initiatives in place can teach important lessons about the development and implementation of permanent solutions to fuel poverty. Solutions can be achieved by combining lessons learned in the UK and the US.

\section{Tags: XPRO}

Ptak, T., A. Nagel, S.M. Radil, and D. Phayre. 2018. Rethinking community: Analyzing the landscape of community solar through the community-place nexus. The Electricity Journal, 31(10): 46-51. https://doi.org/10.1016/j.tej.2018.11.006.

From a geographic perspective, this study analyzes the framing of community in community solar projects. Through an extensive literature review of different sources, it provides a critical perspective for enhancing limited research of an emerging community energy framework. A point is made in which it is established that the concepts of community and solar community have not been defined adequately in their relationship. All of this leads to the misrepresentation of 'community washing'.

Tags: XPRO, XBES, XSOL

Rawls, John. 1971. A Theory of Justice. Harvard University Press.

This book attempts to generalize the traditional theory of the social contract in hope that a theory can be developed that is not as open to obvious objections. The alternative systematic account of justice in this theory might prove superior to the utilitarianism of the traditional approach. This new theory takes classical and well-known ideas and organizes them into a general framework using simplifying devices. This book intends to enable one to see more clearly the main structural features of the alternate conception of justice implicit in the tradition, pointing the way to further elaboration.

Tags: XBES

Reames, T. G. 2016. "A community-based approach to low-income residential energy efficiency participation barriers." Local Environment, 21(12): 1449-1466. https://www.tandfonline.com/doi/full/10.1080/13549839.2015.1136995.

State block grants for no-cost, low-income energy retrofits have been provided by the US Department of Energy's Weatherization Assistance Program since 1976. This case study explores the scaling of the Weatherization Assistance Program -funded energy efficiency retrofits by a community-based approach in five low-income, urban, majority African- 
American neighborhoods, known as the Green Impact Zone, in Kansas City, Missouri. This approach created capabilities for increased recognition of barriers to program participation, facilitating opportunities for new solutions that have otherwise been overlooked under the standard self-referral implementation of the Weatherization Assistance Program.

\section{Tags: XPRO, XBES}

Reames, T. G., M. A. Reiner, and M. B. Stacey. 2018. "An incandescent truth: Disparities in energy-efficient lighting availability and prices in an urban US county." Applied energy, 218: 95-103. https://doi.org/10.1016/j.apenergy.2018.02.143.

The adoption of more energy-efficient light technology such as light-emitting diodes and compact fluorescent lamps is not equitably distributed across socioeconomic groups. Poorer households are less likely to adopt these technologies compared with higherincome households. This case study evaluates disparities in light bulb availability and price across 130 stores in Wayne County, Michigan, covering 4 poverty strata and 5 store types. Findings revealed high-poverty areas had reduced availability and increased cost of energy-efficient bulbs, with higher costs to upgrade from traditional halogen or incandescent bulbs. Poverty and store type were both significant predictors of lightemitting diode availability. Store type was the most significant predictor of variety in light-emitting diode price. Several methods are suggested to achieve a more just energyefficient transition.

\section{Tags: XCHA, XPRO, XCAU, XTEC}

Reina, V. J., and C. Kontokosta. 2017. "Low hanging fruit? Regulations and energy efficiency in subsidized multifamily housing." Energy Policy, 106: 505-513. https://www.sciencedirect.com/science/article/abs/pii/S0301421517302276?via\%3Dihub.

This paper investigates how the energy efficiency of multi-family housing for lowincome households is affected by subsidized housing regulations. A database was constructed that integrates energy use with regulatory, socioeconomic, and physical characteristics of all large multifamily households in New York City, providing a focus on whether a property receives a federal rental subsidy. When multivariate regression models are applied, findings show subsidized properties are associated with higher energy consumption than those at a similar market rate. Public housing tends to consume the most energy compared with other subsidized housing programs. Results suggest regulatory factors constrain investment and consumption decisions in subsidized properties. The report concludes that reducing energy consumption in subsidized housing requires the modification of existing regulations.

Tags: XCHA, XPRO, XMUL, XDAT 
Relf, Grace, Brendon Baatz, and Seth Nowak. 2017. 2017 Utility Energy Efficiency Scorecard. Report U1707. American Council for an Energy-Efficient Economy. https://aceee.org/researchreport/u1707.

This first edition of the Utility Energy Efficiency Scorecard measures quantitative savings and spending, program diversity, business models, and evaluation to assess the 51 largest US electric utilities. Resulting scores showed National Grid MA and Eversource MA performing the best, followed by Pacific Gas \& Electric, Eversource CT, San Diego Gas \& Electric, Baltimore Gas \& Electric, Southern California Edison, Xcel Minnesota, Xcel Colorado, Portland General Electric, and Commonwealth Edison. The scorecard then provides regulators, utilities, and other stakeholders a baseline and roadmap to track performance and increase energy efficiency in the utility sector.

Tags: XPRO, XDAT, XCBA

Ribeiro, David, Eric Mackres, Brendon Baatz, and Rachel Cluett. 2015. "Enhancing Community Resilience through Energy Efficiency." American Council for an Energy-Efficient Economy. https://aceee.org/sites/default/files/publications/researchreports/u1508.pdf.

Many municipalities in the United States lack the resources to respond to a growing number of threats to their residents and economies, including aging infrastructure, economic volatility, and extreme weather. US energy systems are particularly vulnerable because of their interactions with transportation, housing, and business activity. A resilience perspective considers an energy system's external interaction with other systems, including health, water, air, and the broader economic system. Community resilience might be supported by energy efficiency measures by strengthening energy systems and delivering more reliable and affordable energy.

Tags: XCBA, XPRO, XGRI

Ronen, A., D. H. B. Gai, and L. Crampton. 2016. "Can electricity rate subsidies be reallocated to boost low-income solar?” GW Solar Institute Working Paper.

https://solar.gwu.edu/sites/g/files/zaxdzs2391/f/image/Reallocating\%20Subsidized\%20Rates\%20 for\%20Low-Income\%20Solar.pdf.

Rooftop solar could become a source of wealth creation in low-income communities while relieving disproportionate energy burdens. Findings show low-income homeowners' electricity bills could be reduced by $48 \%$ by repurposing flat rate subsidy programs towards rooftop solar investments, saving them nearly $\$ 9,000$ over the lifetime of the solar system.

Tags: XSOL, XCBA

Rose, E., B. Hawkins, B. Conlon, and I. Treitler. 2015. "Assessing the Potential of Social Networks as a Means for Information Diffusion - the Weatherization Experiences (WE) 
Project.” Oak Ridge National Laboratory, ORNL/TM-2014/405.

https://weatherization.ornl.gov/wp-

content/uploads/pdf/WAPRecoveryActEvalFinalReports/ORNL_TM-2014_405.pdf.

This report shows the analyses from ORNL's social network study, the Weatherization Experiences (WE) Project, which is an exploratory study that was conducted as part of the ARRA period Weatherization Assistance Program (WAP) evaluation. The WE Project studied the ability for WAP recipients and staff to influence energy savings outside their homes and day jobs. Previously selected local agencies recruited weatherization staff and recipients of the program in order to conduct the WE Project. Recruits were asked to interview members of their social network that they had shared weatherization information to. The technique used, participatory research, allowed for information to be collected beginning with the first recipient or staff as a node of communication.

The study resulted in four key findings: social networks communicate weatherization experiences; actions and behaviors are influenced by communication; targeted information that might have otherwise been unattainable can be extracted by trained WAP recipients; there are several opportunities to maximize the impact of social network. Results also show how the program utilization process works and how the WAP influences home energy conservation. The research contributes to the discussion on the impact of sharing personal or professional experiences with home-related energy efficiency actions and experiences on the activities and adopted behavior of individuals with whom the information was shared. The study's results were expanded by exploring the potential utilization of existing social networks for the diffusion of new home energy saving information, climate change mitigation and adaptation strategies benefiting vulnerable persons and populations, such as those targeted by WAP, and public health education related to indoor environmental quality (IEQ).

\section{Tags: XPRO, XBES, XHEA}

Ross, L., M. Jarrett, and D. York. 2016. "Reaching More Residents: Opportunities for Increasing Participation in Multifamily Energy Efficiency Programs.” ACEEE Report U1603. https://aceee.org/research-report/u1603.

This report summarizes the challenges to multifamily energy efficiency program participation, identifying practices programs might use to achieve high participation. Conclusions are drawn from program-level data from 20 utilities for 30 multifamily efficiency programs, as well as 13 interviews conducted with program administrators regarding marketing, outreach, and networking to build program participation.

Tags: XPRO, XMUL 
Ross, Lauren, Ariel Drehobl, and Brian Stickles. 2018. "The High Cost of Energy in Rural America: Household Energy Burdens and Opportunities for Energy Efficiency." ACEEE Research Report U1806. https://aceee.org/research-report/u1806.

This report examines energy affordability in rural and small-town America, identifying efficiency as an underused strategy capable of reducing energy burdens by up to $25 \%$. The variety of energy burdens is analyzed across regions and among specific groups. Findings show low-income, elderly, nonwhite, and renter households, as well as residents of manufactured and multifamily housing, spend a larger portion of their income on utilities than the average family. Policies and programs are proposed to increase investments in energy efficiency in small-town and rural communities.

Tags: XCHA, XRUR, XPRO

Roundtree, Jr., Stephan K. 2018. “Community-led Solar Aggregation, Energy Efficiency Outreach and Education in Northern Manhattan." 2018 ACEEE Summer Study on Energy Efficiency in Buildings: Making Efficiency Easy and Enticing. https://aceee.org/files/proceedings/2018/index.html\#/paper/event-data/p408.

Through mass purchasing, popular education, technical support, and outreach, these community-based organizations empower Northern Manhattan residents to take control of their energy future using community-led solar aggregation. A community-led group leads the process of evaluating and selecting solar installers and works to coordinate a comprehensive outreach effort with co-op residents, mainly people of color with low- to moderate-income. The project team works with solar installers and an Energy Democracy Working Group to promote local job creation.

Tags: XPRO, XSOL

Samarripas, Stefan, and Dan York. 2018. "Integrating Energy Efficiency and Solar to Benefit Affordable Multifamily Buildings." 2018 ACEEE Summer Study on Energy Efficiency in Buildings: Making Efficiency Easy and Enticing. https://aceee.org/files/proceedings/2018/index.html\#/paper/event-data/p409.

This research examines several case studies in which affordable multifamily investments in energy efficiency are leveraged against those made in solar projects. Efficiency upgrades, when combined with solar, can achieve large energy cost savings for multifamily buildings, allowing owners to create and preserve more affordable housing options for low-income households. The success of these efforts offers valuable lessons for program administrators and policymakers.

Tags: XPRO, XSOL, XMUL 
Samarripas, Stefan, Dan York, and Lauren Ross. 2017. "More Savings for More Residents: Progress in Multifamily Housing Energy Efficiency." ACEEE Research Report U1702. https://aceee.org/research-report/u1702.

This report is an update for the ACEEE's 2013 multifamily energy program assessment for US metropolitan areas with the most multifamily households. Using policy, utility, and housing data from 2014 and 2015, this report documents how such programs have changed with dynamic housing markets and statewide policy environments. The spending, number, target participants, and offerings of current programs is evaluated, along with their potential for expansion.

Tags: XMUL, XPRO, XDAT

Sanchez, D. R., A. Levine, and L. Tajina. 2018. "Using Partnerships to Drive Energy Efficiency and Preserve Affordability." 2018 ACEEE Summer Study on Energy Efficiency in Buildings: Making Efficiency Easy and Enticing. https://aceee.org/files/proceedings/2018/index.html\#/paper/event-data/p410.

New York City is committed to reducing the city's greenhouse gas emissions by $80 \%$ by 2050 and to the preservation or construction of 300,000 units of affordable housing over 10 years. Programs and financing products were developed to reduce emissions while maintaining affordable rents. This paper explores how Green Housing Preservation Program, Community Retrofit New York City, and the New York City Retrofit Accelerator rely on strategic partnerships to overcome the barriers of funding access and market pressure currently preventing the scaling of energy efficiency projects in affordable housing. Two case studies are presented to demonstrate the importance of these partnerships.

\section{Tags: XPRO}

Scheu, R., P. Azimi, M. E. Guest, A. Gramigna, and B. Stephens. 2018. "Why Equity Matters: Energy Use and Air Quality Disparities by Neighborhood: Stories (and Data) from Families Living in Chicago's Bungalow Belt." 2018 ACEEE Summer Study on Energy Efficiency in Buildings: Making Efficiency Easy and Enticing. https://aceee.org/files/proceedings/2018/index.html\#/paper/event-data/p411.

Families in low-income neighborhoods exhibit increased gas use, greater energy burdens, higher rates of asthma and other respiratory issues, and experience poorer air quality. This paper analyses health and energy impacts across Chicago neighborhoods, including air quality, energy use, asthma rates, and a shallow real estate market analysis. The 2018 ACEEE Summer Study presentation presents case studies, discusses participation in energy and health programs, and tells the stories of families living in these homes and their efforts to improve their homes and health.

Tags: XCAU, XHEA 
Schwartz, J. 2014. "Low Income Consumer Decision Making.” Low Income Energy Issues Forum paper. Washington, DC: Distributed Energy Financial Group LLC. http://defgllc.com/publication/low-income-consumer-decision-making/.

For low-income families, the electric bill exists in the context of other utilities and vital necessities like food, healthcare, childcare, clothing, shelter, and transportation. This research conducts a meta-analysis of 70 articles, presentations, and studies. The results show that low-income families will choose to exercise control over their energy use to free up cash they can apply to other expenses. Seven elements are highlighted that yield the greatest possibility for success by combining advice, feedback, options, literacy, and context. Personalized tools or advice are needed to help low-income families determine the best choices from several options.

\section{Tags: XPRO, XBES, XCAU}

Sexton, Steven. 2015. "Automatic Bill Payment and Salience Effects: Evidence from Electricity Consumption." The Review of Economics and Statistics, 97(2): 229-241.

https://doi.org/10.1162/REST_a_00465.

Automatic bill payment programs eliminated the need for customers to view recurring bills. This causes price salience to decline, consumption to increase, and prices perceived by boundedly rational agents to fall. This report explores the impact of automatic bill payment programs on consumer demand and welfare, empirically testing whether demand is increased by enrollment in such programs. Results show an $8.1 \%$ increase in commercial electricity consumption and a $4.0 \%$ increase in residential consumption. A $6.7 \%$ increase occurs when programs are designed to smooth seasonal variation.

\section{Tags: XDAT, XPRO, XCAU}

Shoemaker, Mary, Annie Gilleo, and Jill Ferguson. 2018. "Reaching Rural Communities with Energy Efficiency Programs.” ACEEE Research Report U1807. https://aceee.org/researchreport/u1807.

Fuel mix, energy use, and infrastructure in rural areas often differ from metropolitan areas, making it challenging to deliver energy efficiency to customers. Rural energy stakeholders, including agricultural customers, rural-based organizations, and smaller utilities, might also be distinctive. This paper describes six energy efficiency programs in rural areas, describing trends across programs and recommending ways to help utilities better serve these communities.

Tags: XPRO, XRUR, XCHA 
Sigrin, Benjamin, and Meghan Mooney. 2018. Rooftop Solar Technical Potential for Low-toModerate Income Households in the United States. Golden, CO: National Renewable Energy Laboratory. NREL/TP-6A20-70901. https://www.nrel.gov/docs/fy18osti/70901.pdf.

Rooftop solar is more prevalent in higher-income households in the United States. Focus is shifting to increasing solar access in low- to moderate-income households with the decline in technology costs and expansion of markets. Solar access must expand more equitably to ensure increased resilience, reduced energy burden, and to hedge against rate changes are available to all ratepayers. A deeper understanding of the LMI market is required to identify the proportion of LMI residents living in buildings suitable for PV, the fraction of electricity needs possibly met by rooftop solar, and the distribution of potential across buildings.

\section{Tags: XSOL, XCHA}

Simms, Kristol, and Lauren Casentini. 2018. "Making Efficiency Easy and Enticing. Leveraging Community Engagement for Maximum Energy Efficiency Impact." 2018 ACEEE Summer Study on Energy Efficiency in Buildings. https://aceee.org/files/proceedings/2018/index.html\#/paper/event-data/p413.

Ameren Illinois Company established a company-wide commitment to serve low- to moderate-income customers beyond traditional weatherization programs, empower underserved communities to participate in the energy efficiency economy, and increase diverse energy spending. This approach focuses on offering customized grants and solidifying relationships with community-based organizations and key local partners. Using metrics for each objective and tracking quantitative and qualitative progress, this report shares the approach, strategy, and progress of this commitment.

\section{Tags: XPRO}

Simon, H. A. 1976. "From substantive to procedural rationality." In T. J. Kastelein, S. K. Kuipers, W. A. Njenhuis, and R. G. Wagnaar (eds) 25 years of economic theory. Boston, MA: Springer. pp. 65-86. https://doi.org/10.1007/978-1-4613-4367-7_6.

Although rational behavior is the core concept in both economics and cognitive psychology, communication between these two disciplines has been infrequent. There are currently no doctoral programs in economics covering the psychological literature of rational choice and no coverage of the economic theories of rationality in psychology programs.

\section{Tags: XBES}

Souba, F., and P. B. Mendelson. 2018. "Chaninik Wind Group: Lessons learned beyond wind integration for remote Alaska." The Electricity Journal, 31(6): 40-47. https://www.sciencedirect.com/science/article/pii/S1040619018301349. 
This report presents a case study highlighting innovations, recommendations, and challenges of wind-diesel integration projects in remote Alaska. Renewable energy technologies are valuable to reduce energy costs despite energy access and affordability proving difficult in remote areas.

Tags: XCBA, XPRO, XSOL, XTEC

Southworth, Katie. 2011. "Pennsylvania's Low-Income Usage Reduction Program (LIURP) Economic Opportunities Studies.

http://www.opportunitystudies.org/repository/File/weatherization/LIURP_Program_Features.pd f.

The Pennsylvania Public Utility Commission has required the state's 15 largest gas and electric utilities to provide low-income usage reduction programs to help low-income households lower their energy costs and reduce consumption through energy education and weatherization. Although the Public Utility Commission monitors such programs through its Bureau of Consumer Services, the programs themselves are administered by distribution utilities. Utilities use a combination of private contractors and nonprofit agencies to implement the programs.

Tags: XPRO

Sovacool, Benjamin K., Paula Kivimaa, Sabine Hielscher, and Kristen Jenkins. 2017. "Vulnerability and resistance in the United Kingdom's smart meter transition." Energy Policy 109: 767-781. https://doi.org/10.1016/j.enpol.2017.07.037.

The Smart Meter Implementation Program creates a legal framework for the installation of smart meters and in-home displays in every UK household by 2020 . The program represents the world's largest and most costly smart meter program. This study investigates the socio-technical barriers facing this program. Using a review of academic literature and an observation of seven major Smart Meter Implementation Program events, this report offers a summary of 67 potential benefits and technical challenges, along with a discussion of nontechnical challenges such as vulnerability and consumer resistance and ambivalence. Therefore, this paper critiques the Smart Meter Implementation Program, offers a review of academic studies, and analyses the intersection between smart metering and other social concerns.

Tags: XTEC, XICT, XPRO

Spillman, Brenda C., Josh Leopold, Eva H. Allen, and Pamela Blumenthal. 2016. "Developing Housing and Health Collaborations Opportunities and Challenges." Urban Institute. https://www.urban.org/sites/default/files/publication/89581/hh_brief_final_0.pdf.

The Affordable Care Act and other health care reforms have provided expanded opportunities at the state, local, and organizational levels, creating collaborations 
between housing and health care providers. This report highlights issues for collaborations and how they are being addressed. Three programs were examined to learn more about challenges and opportunities in housing and health collaborations. Dedicated leadership and commitment to shared goals were identified as the important aspects of successful collaborations. Project viability is improved by the inclusion of a thoughtful and deliberate planning process. Successful partnerships require patience, mutual trust, and education and training for all parties.

Tags: XPRO

Sunstein, C. R., and L. A. Reisch. 2014. "Automatically green: Behavioral economics and environmental protection.” Harv. Envtl. L. Rev., 38: 127.

https://harvardelr.com/2013/11/18/automatically-green/.

Green default rules are decision-making standards that select the green choice as the status quo, requiring consumers to over-ride the green default if they want to be less environmentally responsible. Green default rules might be effective tools for altering outcomes. If well chosen, they are likely to produce large effects in reducing environmental and economic harms resulting from various activities and products, although they might or might not be more expensive to consumers. Before green defaults are applied, choice architects must consider consumer welfare along with other costs and benefits. Green defaults are preferred when both economic and environmental considerations point in their direction. Active choosing is preferred over green default when there is a lack of relevant information, externalities are insignificant, and there are issues maneuvering interest groups.

Tags: XCBA, XBES

Sunter, D. A., S. Castellanos, and D. M. Kammen. 2019. "Disparities in rooftop photovoltaics deployment in the United States by race and ethnicity." Nature Sustainability, 2(1): 71-76. https://doi.org/10.1038/s41893-018-0204-z.

The benefits of rooftop solar might not be evenly distributed across all individuals and communities. This study compares the locations of existing and potential sites for rooftop photovoltaics from Google's Project Sunroof with demographic information from the American Community Survey to explore the relative implementation of rooftop photovoltaics across census tracts grouped by ethnic and racial majority. Results show Hispanic- and Black-majority communities show significantly less rooftop photovoltaics installed, possibly due to racial and ethnic differences in household income and home ownership. However, for the same median income, black- and Hispanic- majority tracts have installed 69\% and 30\% less rooftop solar than nomajority tracts, respectively. White majority tracts have installed $21 \%$ more rooftop PV. When correcting for home ownership, this disparity still remains. Black- and Hispanicmajority communities install $61 \%$ and $45 \%$ less rooftop solar, respectively, when 
compared with no-majority tracts, while white-majority tracts install $37 \%$ more PV. This analysis reveals the ethnic and racial injustice in rooftop solar adoption.

Tags: XSOL, XBES, XCHA

Thorve, S., S. Swarup, A. Marathe, Y. Chungbaek, E. K. Nordberg, and M. V. Marathe. 2018. "Simulating Residential Energy Demand in Urban and Rural Areas." In 2018 Winter Simulation Conference (WSC). IEEE. pp. 548-559. 10.1109/WSC.2018.8632203.

This paper builds hourly disaggregated energy demand estimates at the household level using demographic, physical, and behavioral characteristics of the household. This is made possible using synthetic populations for the rural and urban areas of the state of Virginia. Energy consumption is estimated using behaviors, activities, demographics, weather conditions, physical characteristics of the home, space conditioning fuels, and energy ratings of appliances. Results, when validated against demand curves for Rappahannock county in Virginia, show that the model produces realistic estimates for energy demand.

Tags: XBES, XCHA

Tidwell, J., A. Tidwell, and S. Nelson. 2018. "Surveying the Solar Power Gap: Assessing the Spatial Distribution of Emerging Photovoltaic Solar Adoption in the State of Georgia, USA.” Sustainability, 10(11): 4117. https://doi.org/10.3390/su10114117.

This report explores efforts to mitigate the "local-national gap," described as the disparity in alternative energy use existing across nation-states. This requires an understanding of alternative energy distributions at the local level. Using the case of the state of Georgia, a model is created to analyze how existing adoption trends affect conversation at the local (county) scale. This paper argues the location of gaps in solar adoption can be analyzed using existing work on the Gini Coefficient to measure energy inequity. Results show that communities with increased solar adoption are concentrated in a few counties. This information and the developed model might enable further quantitative analyses of existing solar trends, extending beyond high-adoption areas to communities where little to no adoption has occurred.

Tags: XCHA, XSOL

Tonn, Bruce, David Carroll, Scott Pigg, Michael Blasnik, Greg Dalhoff, Jacqueline Berger, Erin Rose, Beth Hawkins, Joel Eisenberg, Ferit Ucar, Ingo Bensch, and Claire Cowan. 2014. Weatherization Works - Summary Of Findings From The Retrospective Evaluation Of The U.S. Department Of Energy's Weatherization Assistance Program. ORNL/TM-2014/338. Oak Ridge, TN: Oak Ridge National Laboratory. https://www.energy.gov/sites/prod/files/2015/09/f26/weatherization-works-retrospectiveevaluation.pdf. 
This report summarizes results from 20 individual studies comprising the retrospective evaluation conducted on the US Department of Energy Weatherization Assistance Program as administered before the American Recovery and Reinvestment Act of 2009.

Tags: XPRO, XMUL, XMAN

Tonn, Bruce, Erin Rose, Beth Hawkins, and Brian Conlon. 2014. Health and HouseholdRelated Benefits Attributable to the Weatherization Assistance Program. ORNL/TM-2014/345. Oak Ridge, TN: Oak Ridge National Laboratory. https://weatherization.ornl.gov/wpcontent/uploads/pdf/WAPRetroEvalFinalReports/ORNL_TM-2014_345.pdf.

This report monetizes and describes household and health benefits to low-income homes as a result of the WAP. To achieve its goals of increasing efficiency, reducing costs, and improving health and safety, the US Department of Energy provides grants to states, territories, tribes, and the government of Washington, DC, who then fund local agencies to weatherize low-income homes. Weatherization measures include insulation, air sealing, refrigerator replacement, furnace repair and replacement, and ventilation. Weatherization can be deferred if homes present health and safety risks to personnel or are in poor physical condition.

Tags: XPRO, XHEA, XCBA, XMUL, XMAN, XICT

Tonn, Bruce, David Carroll, Erin Rose, Beth Hawkins, Scott Pigg, Daniel Bausch, Greg Dalhoff, Michael Blasnik, Joel Eisenberg, Claire Cowan, Brian Conlon. 2015. "Weatherization Works II-Summary of Findings from the ARRA Period Evaluation of the U.S. Department of Energy's Weatherization Assistance Program." Oak Ridge National Laboratory, ORNL/TM2015/139.https://www.energy.gov/sites/prod/files/2015/09/f26/weatherization-works-II-ARRAperiod-eval.pdf.

In 2009, Oak Ridge National Laboratory (ORNL) was assigned by the U.S. Department of Energy (DOE) to evaluate DOE's low-income Weatherization Assistance Program (WAP) at the same time that the American Recovery and Reinvestment Act of 2009 (ARRA) was passed. WAP's funding was boosted from approximately $\$ 230 \mathrm{M}$ per year to $\$ 5 \mathrm{~B}$ over a three-year period due to the Recovery Act. WAP was evaluated during the Recovery Act period and is known as the 'ARRA period or Recovery Act' evaluation and focuses on PY 2010. This report includes the findings of thirteen studies that were developed during the ARRA period evaluation. The studies estimated program impacts and evaluated program administration.

The findings include: units supported by WAP funds; DOE expenditures on WAP; the average cost to weatherize a DOE; jobs supported directly and indirectly by WAP and leveraged expenditure; energy savings; present value of the program energy cost savings; carbon emissions reduction; present value of the environmental emissions benefits for the program; percentage of households that come into the weatherization program and suffer an extensive set of household budget problems; present value of a 
limited set of health and household-related non-energy benefits for the WAP; average electricity savings in homes weatherized by the Puerto Rico program; information about weatherization experiences shared by weatherization clients; analysis of Medicaid records; average annualized electricity consumption for a refrigerator; causes of weatherization services being deferred; and number of new weatherization training centers.

\section{Tags: XPRO, XBES, XCBA, XHEA}

Tonn, B., E. Rose, and B. Hawkins. 2015. Survey of Recipients of Weatherization Assistance Program Services: Assessment of Household Budget and Energy Behavior Pre-to PostWeatherization. ORNL/TM-2015/64. Oak Ridge, TN: Oak Ridge National Laboratory. https://info.ornl.gov/sites/publications/Files/Pub54436.pdf.

This report analyzes survey data collected from the US Department of Energy Weatherization Assistance Program. The US Department of Energy provides grants to states, territories, tribes, and the government of Washington, DC, who then fund local agencies to weatherize low-income homes. The program operates across all climate zones of the Unites States and weatherizes a large variety of homes, including multifamily buildings, mobile homes, and single-family detached units.

Tags: XPRO, XMUL, XMAN

Tonn, B., B. Hawkins, and E. Rose. 2016. "Assessment of the American Recovery and Reinvestment Act Upon the Department of Energy Weatherization Assistance Program." Review of Policy Research, 33(2): 178-200. https://doi.org/10.1111/ropr.12164.

During the American Recovery and Reinvestment Act of 2009, the Department of Energy Weatherization Assistance Program received \$5 billion in funding. States and local weatherization agencies were surveyed to assess their experiences during this period. Numerous issues arose due to the increase in funding, including increased political visibility resulting in a shift of organizational responsibility, an increase in media attention, increased federal oversight, and the passing of new laws and regulations. Coupled with this increase in oversight, the requirement that the Weatherization Assistance Program operate under the Davis-Bacon Act of 1931 saw an increase in program costs. Although there is concern that the American Recovery and Reinvestment Act funds would damage nonfederal funding leveraging relationships, two-thirds of grantees and $40 \%$ of subgrantees believe that long-term impacts will be positive.

Tags: XPRO, XCHA, XCBA

Tonn, B., E. Rose, and B. Hawkins. 2018. "Evaluation of the U.S. Department of Energy's weatherization assistance program: Impact results." Energy Policy 118: 279-290. https://www.sciencedirect.com/science/article/abs/pii/S0301421518301836. 
This paper presents the results of impact evaluations of the Department of Energy's Weatherization Assistance Program for program years 2008 and 2010, with the latter falling during the American Recovery and Reinvestment Act period. During program years 2008 and 2010, 98,000 and 332,000 units were weatherized, respectively.

Estimated savings are 2.3 trillion Btu, with cost savings of $\$ 420$ million in program year 2008 , and 7.6 trillion Btu with cost savings of $\$ 1.2$ billion in program year 2010. To reflect health and household benefits and environmental. Per unit weatherized, the average benefit in program year 2008 is $\$ 22,000$, and for program year 2010, they are $\$ 20,000$.

Tags: XPRO, XCBA, XBES, XHEA

Treadway, N. 2018. The Long Struggle Continues: Improving Service to Low-Income Customers in the Utility Sector. EcoPinion Consumer Survey Report 31. Washington, DC: Distributed Energy Financial Group LLC. http://defgllc.com/publication/the-long-strugglecontinues-improving-service-to-low-income-customers-in-the-utility-sector/.

This survey presents responses to 19 questions from households with annual incomes below $\$ 50,000$. Findings show low-income consumers are eager to be informed of ways to lower their utility bills. Utilities must listen to consumers and challenge underlying assumptions with traditional programs, assistance measures, and service offerings. These results were first shared at the November 2017 Forum workshop in Atlanta.

\section{Tags: XBES, XCHA}

Ulrich, Elaine, Monisha Shah, Joseph Pereira, David Hepinstall, David Feldman, Jeffrey Cook, Amy Hollander, Gillian Weaver, Kosol Kiatreungwattana, and Jason Edens. 2018. "Using Federal Energy Assistance Funds for PV to Reduce Energy Burden for Low Income Households." 2018 ACEEE Summer Study on Energy Efficiency in Buildings: Making Efficiency Easy and Enticing. https://aceee.org/files/proceedings/2018/index.html\#/paper/eventdata/p412.

Solar photovoltaics, compared with innovative financing options, present an attractive option for helping low-income customers reduce their energy burden. The Department of Energy's Weatherization Assistance Program and the Solar Energy Technologies Office are collaborating with the National Renewable Energy Laboratory to provide grantees with technical support and guidance to gain approval for the use of Weatherization Assistance Program funds on photovoltaics. Colorado and New York State show early examples of Weatherization Assistance Program grantees demonstrating cost reductions from photovoltaics. The Low-Income Heating and Energy Assistance Program also shows few states incorporating photovoltaics to reduce household energy burden. The National Renewable Energy Laboratory and the Solar 
Energy Technologies Office are exploring how solar business models might align with the Low-Income Home Energy Assistance Program assistance model.

Tags: XPRO, XSOL

United Nations Development Program. 2005. "Time for Bold Ambition Together We Can Cut Poverty in Half." United Nations Development Program. http://www.undpaciac.org/publications/other/undp/reports/annualreport-05e.pdf.

This report describes the five-year review of the United Nations Millennium Summit. The United Nations has spearheaded reports charting methods to achieve global safety and prosperity, including assessments by the United Nations High-Level Panel on Threats, Challenges, and Change, the United Nations Millennium Project, and the United Nations Secretary General's report combining the conclusions of both together. It also explores United Nations reform on a scale unseen since the organization's inception.

Tags: XPRO

U.S. Department of Energy. 2015. National Evaluations: Summary of Results. https://nascsp.org/wpcontent/uploads/2017/09/WAP_NationalEvaluation_WxWorks_v14_blue_82052015.pdf.

This report presents a summary of two multiyear, peer-reviewed, statistically robust national evaluations of the Department of Energy Weatherization Assistance Program led by the Oak Ridge National Laboratory. The retrospective evaluation covers program year 2008, reflecting a typical year of Weatherization Assistance Program operation. The Recovery Act Evaluation covers program year 2010 and provides an analysis of the Department of Energy program to promote economic recovery and create jobs as part of the American Recovery and Reinvestment Act of 2009.

Tags: XPRO, XDAT, XCBA

U.S. Department of Energy. 2017. "Clean Energy for Low Income Communities Accelerator (CELICA): Year 1 Review”. Better Buildings: U.S. Department of Energy. https://www.energy.gov/sites/prod/files/2017/12/f46/CELICA-year-review.pdf.

This article presents the Year 1 review of the Clean Energy for Low Income Communities Accelerator (CELICA). The objective of CELICA is to lower energy bills for low-income communities by implementing voluntary partnerships between the U.S. Department of Energy (DOE) and state and local governments. CELICA's activities in year 1 comprised the arrangement of four learning networks; coordination of a two-day peer exchange workshop for 8 states that were interested in integrating energy efficiency and distributed renewables in low income communities; assistance to partners in action plan development; and organization of a one-day workshop at the Better Buildings 
Summit. CELICA developed program planning tools for partners including: Lowincome Energy Affordability Data Tool (LEAD); Baseline Assessment Guide; Program Funding Catalog; and Action Plan Template \& Guide.

\section{Tags: XPRO, XBES, XDAT}

U.S. Energy Information Administration. 2000. Energy Consumption and Renewable Energy Development Potential on Indian Lands. SR/CNEAF/2000-01. Table ES-3. https://www.energy.gov/sites/prod/files/2017/06/f34/EIA2000.pdf.

This report investigates prices, renewable energy potential, and electricity use in Tribal Jurisdictional Statistical Areas (TJSAs) and Federally Recognized Indian Reservations in Oklahoma. Principal results show disproportionate access to electricity, higher energy burden, and the potential for renewable energy development in some Indian lands. Results show there exists the greatest need for electrification in the Navajo Reservation in Arizona, with biomass, wind, and rooftop solar being viable renewable generation options.

\section{Tags: XRUR, XCHA}

Verclas, K. 2018. "Electric vehicle and solar energy pilot: Opportunity to address suburban energy challenges." The Electricity Journal. https://www.sciencedirect.com/science/article/pii/S1040619018301453.

This case study presents a method to combine electric vehicle and solar rooftop incentives. Widespread adoption of these technologies could increase access to renewable energy and electric vehicles and reduce costs of electricity and transportation for vulnerable families.

Tags: XPRO, XCBA, XSOL, XTEC

Verclas, Kristen, and Eric Hsieh. 2018. "From utility disconnection to universal access." The Electricity Journal. https://www.sciencedirect.com/science/article/pii/S104061901830143X?via\%3Dihub.

This case study presents lessons learned from disconnection policies primarily in Minnesota in efforts to extrapolate findings to tackle energy insecurity in other states and the nation as a whole. The case study discusses the relevance of US universal access to the utility shut-off challenge.

Tags: XCHA, XPRO 
Vote Solar. 2018. "The Vision for U.S. Community Solar: A Roadmap to 2030." Vote Solar and GTM Research. https://votesolar.org/policy/policy-guides/shared-renewablespolicy/csvisionstudy/\#reportdownload.

Customer demand and affordable clean solar energy have made community solar the fastest growing solar market segment with more than $1 \mathrm{GW}$ of installed capacity. Community solar provides access to solar energy regardless of housing type and income level. However, the model has yet to achieve scale because most states lack community solar policies or are not reaching a diverse customer base. Access can be expanded with improvements in program design and implementation, financing solution, and customerfocused offerings. This study evaluates the market potential of community solar and identifies pathways for adoption nationwide by 2030 .

\section{Tags: XPRO, XCBA}

Waite, Wayne, Sara Baldwin Auck, Mari Hernandez, and Erica McConnell. 2018. "Shifting the Burden: How Utility Rate Design Changes are Impacting Energy Costs and Clean Energy Access for Low-Income Renters." 2018 ACEEE Summer Study on Energy Efficiency in Buildings: Making Efficiency Easy and Enticing. https://aceee.org/files/proceedings/2018/index.html\#/paper/event-data/p415.

This research examines utility rate design and solar photovoltaics compensation structures in California. The report first investigates the impact of default time-of-use rates on energy costs for low-income and multifamily households. Secondly, the paper assesses the possibility that changing energy cost and solar compensation could have an adverse effect on the value proposition of solar photovoltaics in multifamily housing. Finally, the implications of these new compensation and rate structures are considered along with methods to achieve greater energy equity. Findings show that time-of-use structures can increase cost burdens and have adverse effects on low-income consumers, potentially affecting the value proposition of solar photovoltaics and access to solar. The report concludes by providing methods to mitigate cost risks and expand energy opportunities in low-income communities.

Tags: XSOL, XMUL

Walton, K. C. 2014. "Renewable energy for low income clients: benefits beyond the money." Energy Procedia. 57: 826-833. https://www.sciencedirect.com/science/article/pii/S1876610214016580?via\%3Dihub.

The Sustainable Energy Resources for Consumers grants under the American Recovery and Reinvestment Act aim to expand weatherization to "materials, benefits, and renewable and domestic energy technologies" that were not already covered. Appropriate technology is defined as an approach to implementation characterized by sound and creative engineering that recognizes the economic, social, and environmental components. Two such grants were awarded in Michigan, one to the Oakland 
Livingston Human Service Agency in Southeast Michigan and one to the Muskegon and Oceana Community Action Partnership in West Michigan. This paper looks at qualitative indicators to investigate whether clients experienced benefits beyond monetary savings from renewable systems installed in their homes and whether those benefits vary between the photovoltaic and solar thermal systems.

Tags: XBES, XPRO, XCBA, XSOL

Wells, E. M., M. Berges, M. Metcalf, A. Kinsella, K. Foreman, D. G. Dearborn, and S. Greenberg. 2015. "Indoor air quality and occupant comfort in homes with deep versus conventional energy efficiency renovations." Building and Environment 93: 331-338. https://www.sciencedirect.com/science/article/pii/S0360132315300354.

There is currently a poor understanding of the impact of increased energy efficiency on indoor air quality. This longitudinal study compares occupant comfort and indoor air quality in 12 single-family, low-income homes renovated to an Energy Star or Deep Energy Retrofits standard. In the study, 237 indoor air quality measurements were taken from 4 rooms per visit after a median of 18 months postrenovation. In adjusted regression models, the average difference in indoor air quality parameters in Deep Energy Retrofits versus Energy Star homes were: carbon dioxide: 43.7 ppm (-18.8, 106.2); relative humidity: $0.4 \%(-1.1,1.8)$; temperature: $-0.3^{\circ} \mathrm{C}(-1.2,0.6)$; and total volatile organic compounds: 198 ppb (-224, 620). Residents in Energy Star homes were significantly more likely to report their homes were comfortable, likely due to difficulties faced with new heating system technology in Deep Energy Retrofits homes. No differences were found between indoor air quality measurements from Deep Energy Retrofits and ES homes, although education is recommended prior to incorporation of new technologies.

Tags: XPRO, XBES, XTEC, XDAT

White, L.V. and N.D. Sintov. 2019. "Health and financial impacts of demand-side response measures differ across sociodemographic groups.” Nature Energy. https://www.nature.com/articles/s41560-019-0507-y.

This article analyzes how demand- side response should revalue the way energy is invoiced for specific demographic groups, such as elderly people or with specific health conditions. These demographic groups face challenges that force them to consume more energy, and that also combine with social and financial pressure. The same time of use (TOU) rates, rather than control and measure, disproportionately increases bills and predicts worse health results for households with disabled and ethnic minority occupants than those for non-vulnerable counterparts. Here we examine 7,487 households that took part in a randomized control TOU pilot in the southwestern United States. The paper 
examines more than seven thousand households that took part in a randomized control of the TOU pilot in the southwestern United States.

\section{Tags: XPRO, XBES, XHEA}

Wierzba, A. L., M. A. Morgenstern, S. A. Meyer, T. H. Ruggles, and J. Himmelreich. 2011. "A study to optimize the potential impact of residential building energy audits." Energy Efficiency 4(4): 587-597. https://doi.org/10.1007/s12053-011-9106-X.

This report presents a proactive method of identifying homes for energy audits targeting older low-income neighborhoods. In Colorado Springs, 14 homes in the Mill Street Neighborhood received thermal audits, including Energy-10 modeling and blower door tests. The results are extrapolated over the 145 homes in the neighborhood. The paper discusses the skewed distributions of $\mathrm{R}$ (aver) values and building sizes and the normally distributed values for air changes per hour the best

The report then presents a method of identifying unusual occupant behavior relative to building quality by comparing a Building Thermal Performance Index with the Home Heating Index. Estimates predict a $\$ 146,500$ investment in retrofit materials will yield total neighborhood savings of $9.1 \times 10(6) \mathrm{kBtu}$ in energy, $\$ 64,000$ in utility costs, and 555 US tons $(5.0 \times 10(5) \mathrm{kg})$ in greenhouse gas emissions, with a payback time of 2.3 years. This method provides data supporting grant proposals to purchase materials for further retrofits and supports municipal demand-side management programs.

\section{Tags: XPRO, XCBA}

Wimberly, J. 2017. The Best Service for Utility Customers with the Least. EcoPinion Consumer Survey Report 27. Washington, DC: Distributed Energy Financial Group LLC. http://defgllc.com/publication/the-best-service-for-utility-customers-with-the-least/.

This report states that utilities must seek to provide the best service to low-income customers who tend to face difficulty paying heating and electric bills. Survey results show two-thirds of participants reported that it was "somewhat hard" to "extremely hard" to save energy. Low-income consumers are most comfortable turning to their local utility for help and need more and better ways to help themselves.

\section{Tags: XBES, XCAU}

Wimberly, J. 2016. The Nut Within The Nut: Focusing on Truly Vulnerable Energy Consumers. EcoPinion Consumer Survey Report 23. Washington, DC: Distributed Energy Financial Group LLC. http://defgllc.com/publication/focusing-on-truly-vulnerable-energy-consumers/.

When surveyed, low- to moderate-income consumers reported that there is much more that can be done to expand options and improve utility service in their communities. This report investigates whether, by focusing on the neediest Americans, utilities might improve customer service and program delivery for all customers, stating that utility 
management should see the need for a well-integrated, holistic approach to better serve low-income customers. Missing links were identified between payment agreements and energy assistance and between payment arrangements or energy assistance and efficiency programs.

Tags: XPRO, XCAU, XCHA

Winner, Brooks, Suzanne MacDonald, Juliette Juillerat, and Lisa Smith. 2018. "Bridging the Rural Efficiency Gap: Expanding Access to Energy Efficiency Upgrades in Remote and High Energy Cost Communities." 2018 ACEEE Summer Study on Energy Efficiency in Buildings: Making Efficiency Easy and Enticing. https://aceee.org/files/proceedings/2018/index.html\#/paper/event-data/p416.

Islands and rural communities face financial, awareness, and geographic barriers that make it difficult to invest in home energy upgrades, creating a "rural energy efficiency gap." In partnership with the Department of Energy, the Maine Governor's Energy Office and the Island Institute researched rural energy efficiency gaps in four states and identified a set of "bridging models." These are community-based approaches, program designs, and policy tools that help close the gap and connect rural communities with financing, information, and other support required to benefit from energy efficiency. "Weatherize" campaigns and other community-based strategies are accelerating the adoption of energy efficiency in tribal villages, low-income communities, and other underserved areas in Alaska and Northern New England. This report presents data on the rural energy efficiency gap, identifying barriers to energy efficiency in rural areas. It also focuses on methods for residents with high thermal energy burdens to increase safety and comfort in their homes while reducing energy bills.

\section{Tags: XPRO, XRUR}

Wolske, K. S., P. C. Stern, and T. Dietz. 2017. "Explaining interest in adopting residential solar photovoltaic systems in the United States: Toward an integration of behavioral theories." Energy research \& social science, 25: 134-151. https://doi.org/10.1016/j.erss.2016.12.023.

This study draws from the theory of planned behavior, value-belief-norm theory, and diffusion of innovations theory to investigate the social and psychological determinants of interest in residential solar. A theoretical framework is created and tested using survey data from 904 non-adopter homeowners to identify potential methods of intervention. Findings show consumers see solar electricity as an innovative technology, consumer good, and environmental benefit. Individuals drawn to novel products and those who trust installers and believe solar will provide a personal benefit are more likely to contact an installer. Results also suggest that marketing efforts aimed at environmentally conscious individuals might need to emphasize nonenvironmental benefits and support leveraging with trusted social networks to convey the benefits of 
solar. The report concludes by discussing the usefulness of the created framework along with implications for marketers and policymakers.

Tags: XSOL, XBES

Yu, J., Z. Wang, A. Majumdar, and R. Rajagopal. 2018. "DeepSolar: A Machine Learning Framework to Efficiently Construct a Solar Deployment Database in the United States." Joule, 2(12): 2605-2617. https://doi.org/10.1016/j.joule.2018.11.021.

This study constructed a comprehensive high-fidelity solar deployment database for the contiguous United States using DeepSolar, a framework that analyzes satellite imagery to identify the sizes and global positioning system locations of solar photovoltaic panels. Results show solar deployment density peaks at a population density of 1,000 people per square mile has an inverse correlation with the Gini index of income inequality, and increases with annual household income with an asymptote at around $\$ 150 \mathrm{k}$. Solar deployment was found to "trigger" at a threshold solar radiation of $4.5 \mathrm{kWh} / \mathrm{m}^{2} /$ day. The research also constructed a predictive model that estimates the solar deployment density at the census tract level. This database is a publicly available resource to build comprehensive economic and behavioral models, further uncover solar deployment patterns, and support the adoption of solar electricity.

Tags: XDAT, XSOL, XBES

Zhang, H., Y. Vorobeychik, J. Letchford, and K. Lakkaraju. 2016. "Data-driven agent-based modeling, with application to rooftop solar adoption." Autonomous Agents and Multi-Agent Systems 30(6): 1023-1049. https://link.springer.com/article/10.1007\%2Fs 10458-016-9326-8.

This study designs and applies an agent-based modeling framework to forecast the aggregate and individual residential adoption of rooftop solar in San Diego County, demonstrating that the model successfully forecasts adoption trends and provides a quantification of uncertainty in its predictions. This model is intended to aid in the development of better incentive structures aimed at increasing solar adoption. The study reveals that a simple heuristic search algorithm could lead to plans that are more effective than current subsidies in San Diego County. The report finally explores an exclusive class of policies providing free systems to low-income households that have proved more effective than any incentive-based policies analyzed thus far.

\section{Tags: XCBA, XBES, XCHA, XSOL, XDAT}

Zhang, W., Robinson, C., Guhathakurta, S., Garikapati, V. M., Dilkina, B., Brown, M. A., and Pendyala, R. M. 2018. "Estimating residential energy consumption in metropolitan areas: A microsimulation approach.” Energy, 155: 162-173. https://www.sciencedirect.com/science/article/abs/pii/S0360544218307849?via\%3Dihub. 
This study proposes a bottom-up model using publicly available datasets to estimate residential energy demand in the United States. The model matches records in the Residential Energy Consumption Survey with Public Use Microdata samples. This process provides a representative population with an energy consumption distribution by source, reflecting regional energy use patterns. The study also ensures representativeness by controlling household variables such as number of vehicles, household type, household size, number of rooms, structure type, tenure, heat fuel type, and income. Person-level variables are also controlled, including employment status, race, age, and gender. This process produces a synthetic household energy distribution at a neighborhood scale. Testing and validation was conducted using data from the Atlanta metropolitan area.

\section{Tags: XCBA, XBES, XCHA}

Zhao, D., A. P. McCoy, P. Agee, Y. Mo, G. Reichard, and F. Paige. 2018. "Time effects of green buildings on energy use for low-income households: A longitudinal study in the United States." Sustainable Cities and Society, 40: 559-568. https://doi.org/10.1016/j.scs.2018.05.011.

There is little to no available evidence of the effectiveness of green building policy in affordable housing programs in the context of financial savings and energy performance. This study investigates time effects of such policy on the energy performance in low-income households. Profile analysis and MANOVA were conducted using monthly energy use data collected over three years from 310 residential units. Results show the energy performance of green buildings is consistent over years; occupant type inconsistently affects energy use; and construction type, apartment size, and technology level all consistently and significantly affect energy use. Results also suggest financial savings of $\$ 648$ per year due to reduced energy use, equivalent to $3.5 \%, 5.6 \%$, and $9.3 \%$ of annual income for low-income, very low-income, and extremely low-income families, respectively. These savings represent a $26.6 \%-37.5 \%$ reduction of expenditure for low-income households. These results strongly suggest the diffusion of green building practice and green building incentives is resulting in affordable housing systems.

\section{Tags: XPRO, XCBA, XBES}

Zhao, T., L. Bell, M. W. Horner, J. Sulik, and J. Zhang. 2012. "Consumer responses towards home energy financial incentives: A survey-based study.” Energy Policy, 47: 291-297. https://www.sciencedirect.com/science/article/abs/pii/S0301421512003758?via\%3Dihub.

Using a household mailing survey in Florida, this report examines two forms of incentives, interest-free loans and tax credits to investigate impacts of financial incentives on homeowner's decision-making towards six energy-efficient and renewable energy products. Results revealed that high investment cost was a major concern hindering purchase activities and that homeowners were much less attracted to interestfree loans than to valued tax credits and financial incentives. Current federal tax credits 
were found to attract only $2 \%-12 \%$ of homeowners to buy energy-efficient and renewable energy products. Costly products such as solar panels showed an especially low participation rate. The participation rate was also lower for low-income families in older residences. This study serves to better the understanding of social and economic aspects of consumer decision-making on alternative energy and energy efficiency.

Tags: XBES, XPRO 